\title{
Article
}

\section{Direct observation of intermediates in a thermodynamically controlled solid state dynamic covalent reaction}

Ana M Belenguer, Giulio Isacco Lampronti, David J. Wales, and Jeremy Keith Morris Sanders

J. Am. Chem. Soc., Just Accepted Manuscript • Publication Date (Web): 14 Oct 2014

Downloaded from http://pubs.acs.org on October 15, 2014

\section{Just Accepted}

"Just Accepted" manuscripts have been peer-reviewed and accepted for publication. They are posted online prior to technical editing, formatting for publication and author proofing. The American Chemical Society provides "Just Accepted" as a free service to the research community to expedite the dissemination of scientific material as soon as possible after acceptance. "Just Accepted" manuscripts appear in full in PDF format accompanied by an HTML abstract. "Just Accepted" manuscripts have been fully peer reviewed, but should not be considered the official version of record. They are accessible to all readers and citable by the Digital Object Identifier (DOI®). "Just Accepted" is an optional service offered to authors. Therefore, the "Just Accepted" Web site may not include all articles that will be published in the journal. After a manuscript is technically edited and formatted, it will be removed from the "Just Accepted" Web site and published as an ASAP article. Note that technical editing may introduce minor changes to the manuscript text and/or graphics which could affect content, and all legal disclaimers and ethical guidelines that apply to the journal pertain. ACS cannot be held responsible for errors or consequences arising from the use of information contained in these "Just Accepted" manuscripts. 


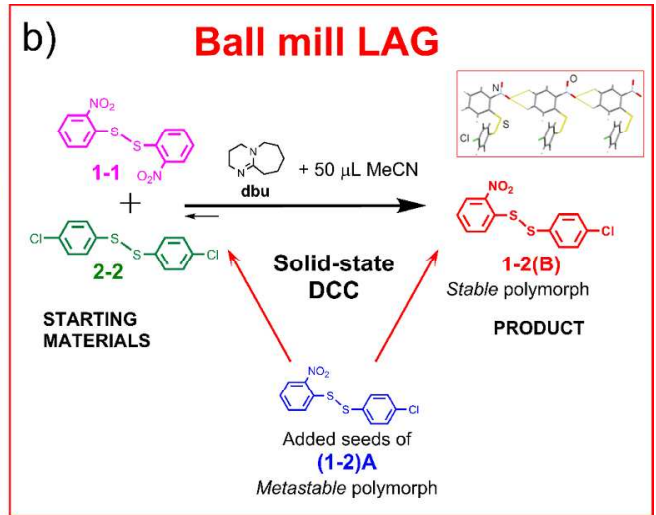

Figure 1 Solid state DCC reaction through ball mill grinding: (a) under neat and (b) under LAG conditions. From the solid state DCC reaction of the homodimers (CCDC1 codes ODNPDS02 and DCPHDS for 1-1 and 22 respectively) only the relevant stable polymorph of the heterodimer crystallizes. When seeds of the metastable polymorph of the heterodimer are introduced in the grinding system two simultaneous and competitive pathways are possible: a direct polymorph interconversion (route to the right) or a sequential transformation from (1-2)A to homodimers to (1-2)B (route to the left) under ball mill neat grinding conditions, or vice versa under ball mill LAG conditions. Details of (1-2)A (CCDC code FUQLIM01) and (1-2)B (CCDC code FUQLIM) have been previously reported. $177 \times 70 \mathrm{~mm}(300 \times 300$ DPI $)$ 
Figure 2 Solid state DCC studies reacting 1-1 and 2-2 in equimolar ratio (no added seeds of 1-2) in the presence of catalyst ( $\mathrm{dbu}$ ). Figures framed in blue on the left represent ball mill neat grinding conditions. Figures framed in red on the right represent ball mill LAG conditions using $50 \mu \mathrm{L} \mathrm{MeCN.} \mathrm{a)} \mathrm{and} \mathrm{b):} \mathrm{reaction}$ scheme. c) and d): kinetic curves prepared as obtained from the Rietveld quantitative phase analysis. e) and f): free energy diagrams.
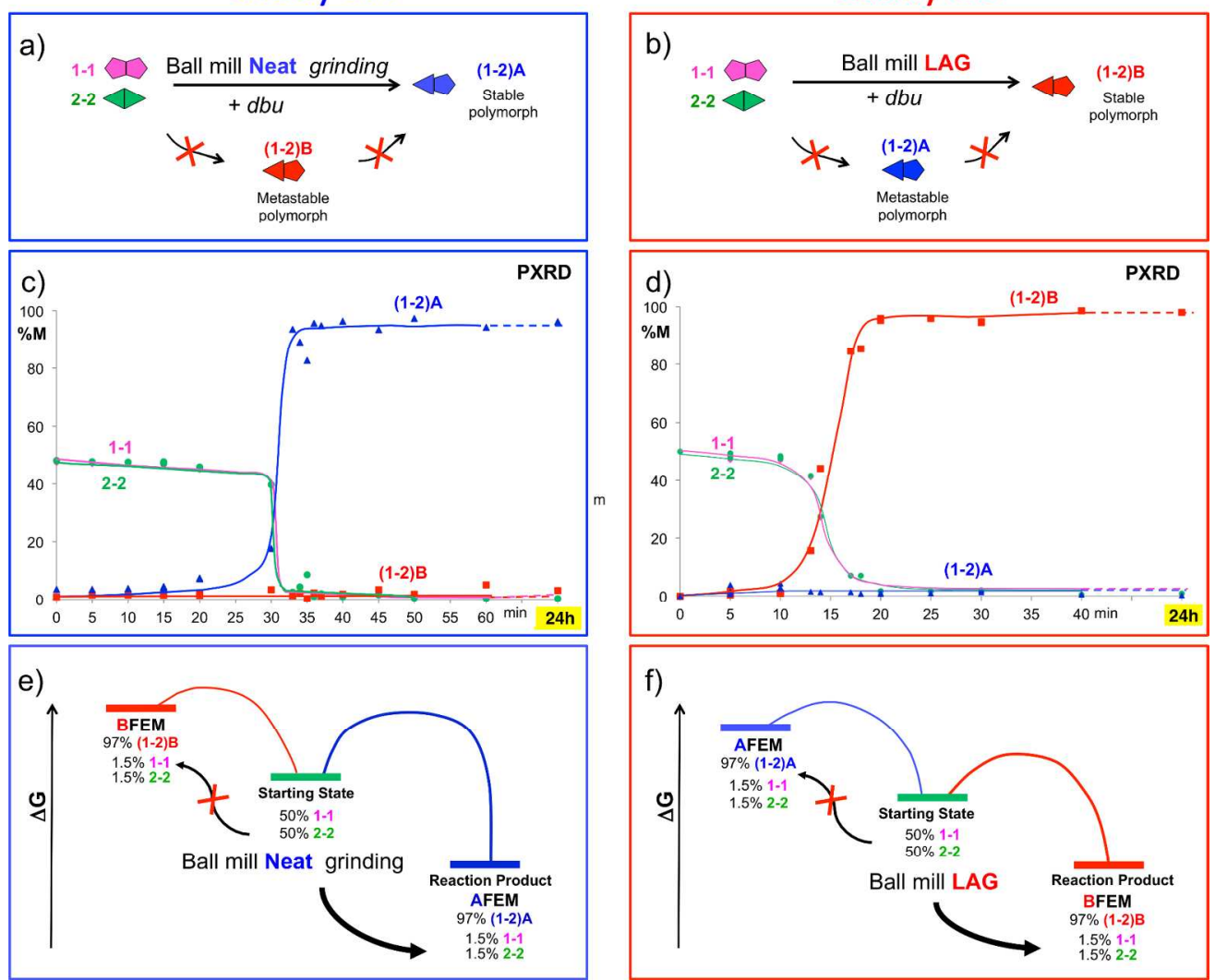
Study 2A
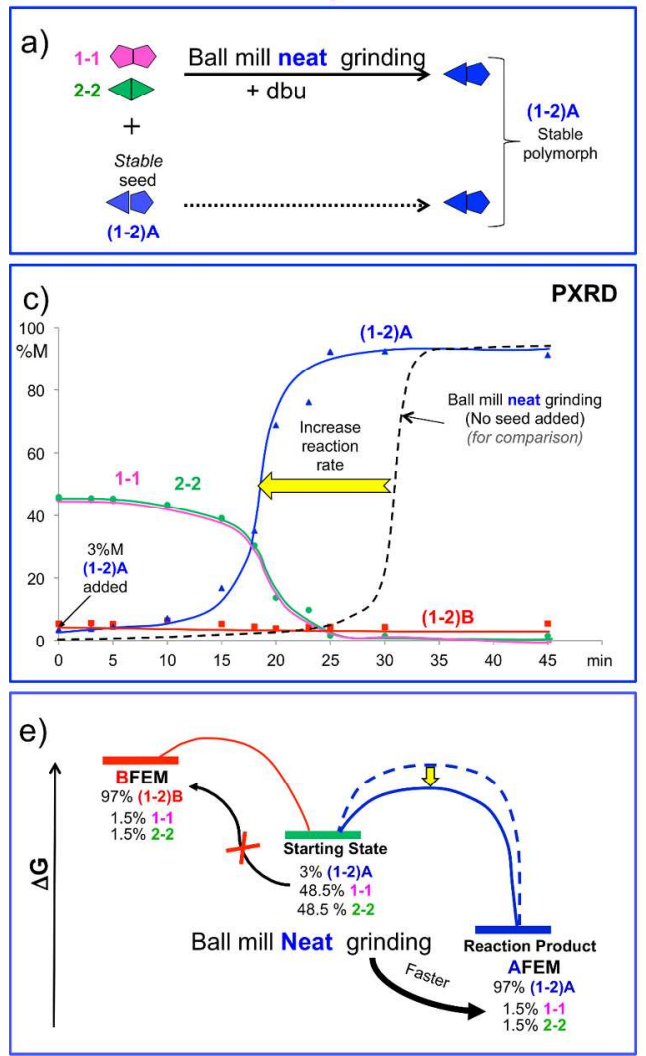

Study 2B
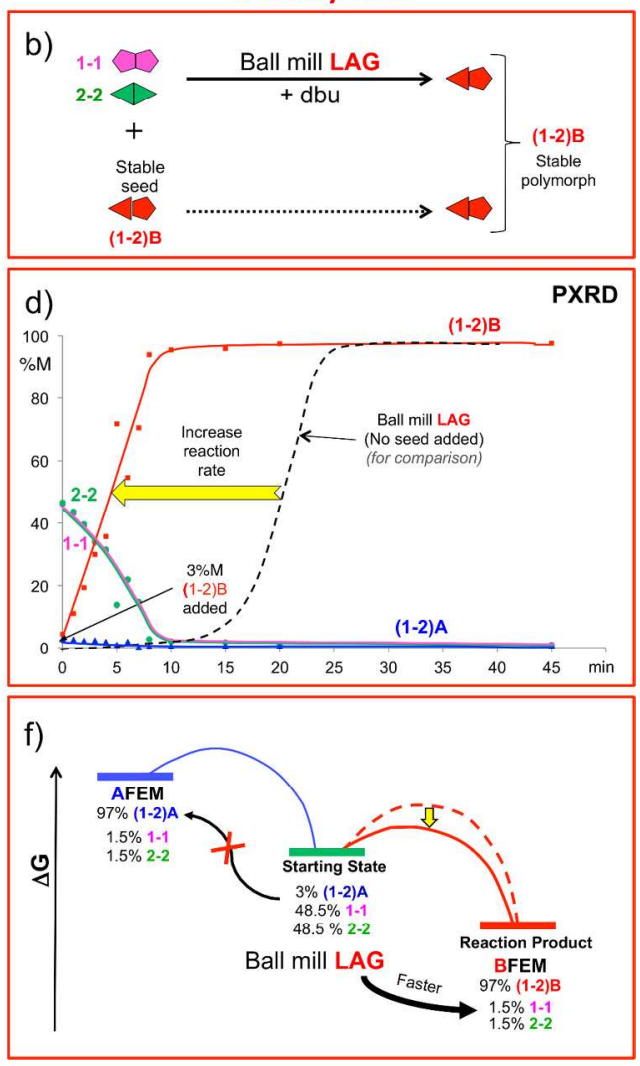

Figure 3 Solid state DCC studies reacting $1-1$ and 2-2 in equimolar ratio seeded with $3 \% \mathrm{M}$ of the stable polymorph of 1-2 in the presence of catalyst (dbu). Figures framed in blue on left represent ball mill neat grinding conditions. Figures framed in red on the right represent ball mill LAG conditions using $50 \mu \mathrm{L} \mathrm{MeCN}$. a) and b): reaction scheme. c) and d): kinetic curves prepared as obtained from the Rietveld quantitative phase analysis. e) and f): free energy diagrams. $177 \times 149 \mathrm{~mm}(300 \times 300$ DPI) 
Study 3 A
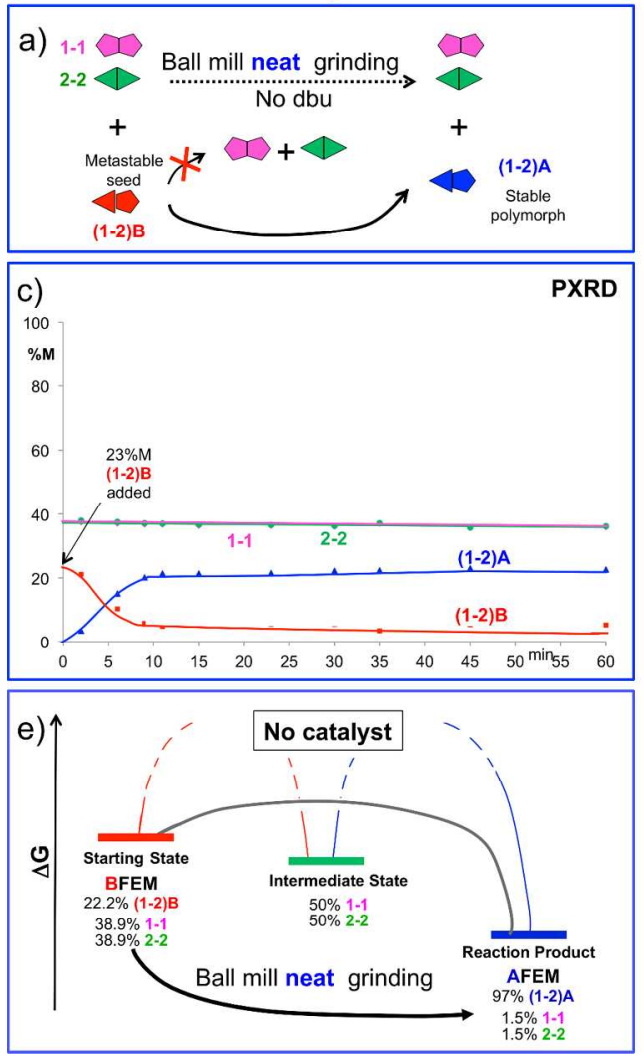

Study 3B
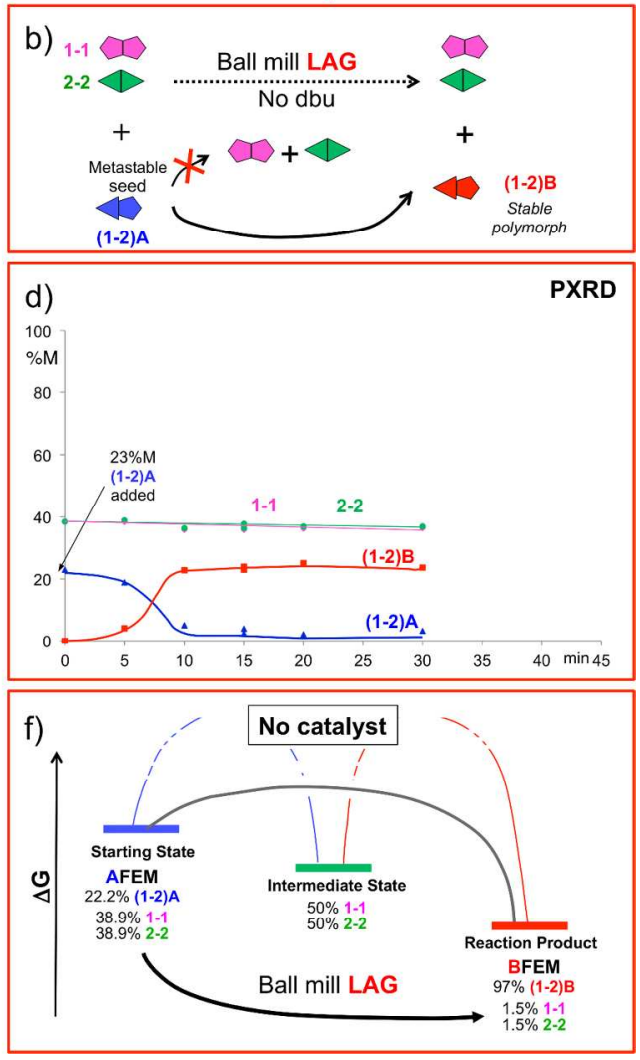

Figure 4 Solid state DCC studies reacting 1-1 and 2-2 in equimolar ratio seeded with $23 \% \mathrm{M}$ of the metastable polymorph of $1-2$, in the absence of catalyst (dbu). Figures framed in blue on left represent ball mill neat grinding conditions. Figures framed in red on the right represent ball mill LAG conditions using 50 $\mu \mathrm{L}$ MeCN. a) and b): reaction scheme. c) and d): kinetic curves prepared as obtained from the Rietveld quantitative phase analysis. e) and f): free energy diagrams. $177 \times 149 \mathrm{~mm}(300 \times 300 \mathrm{DPI})$ 

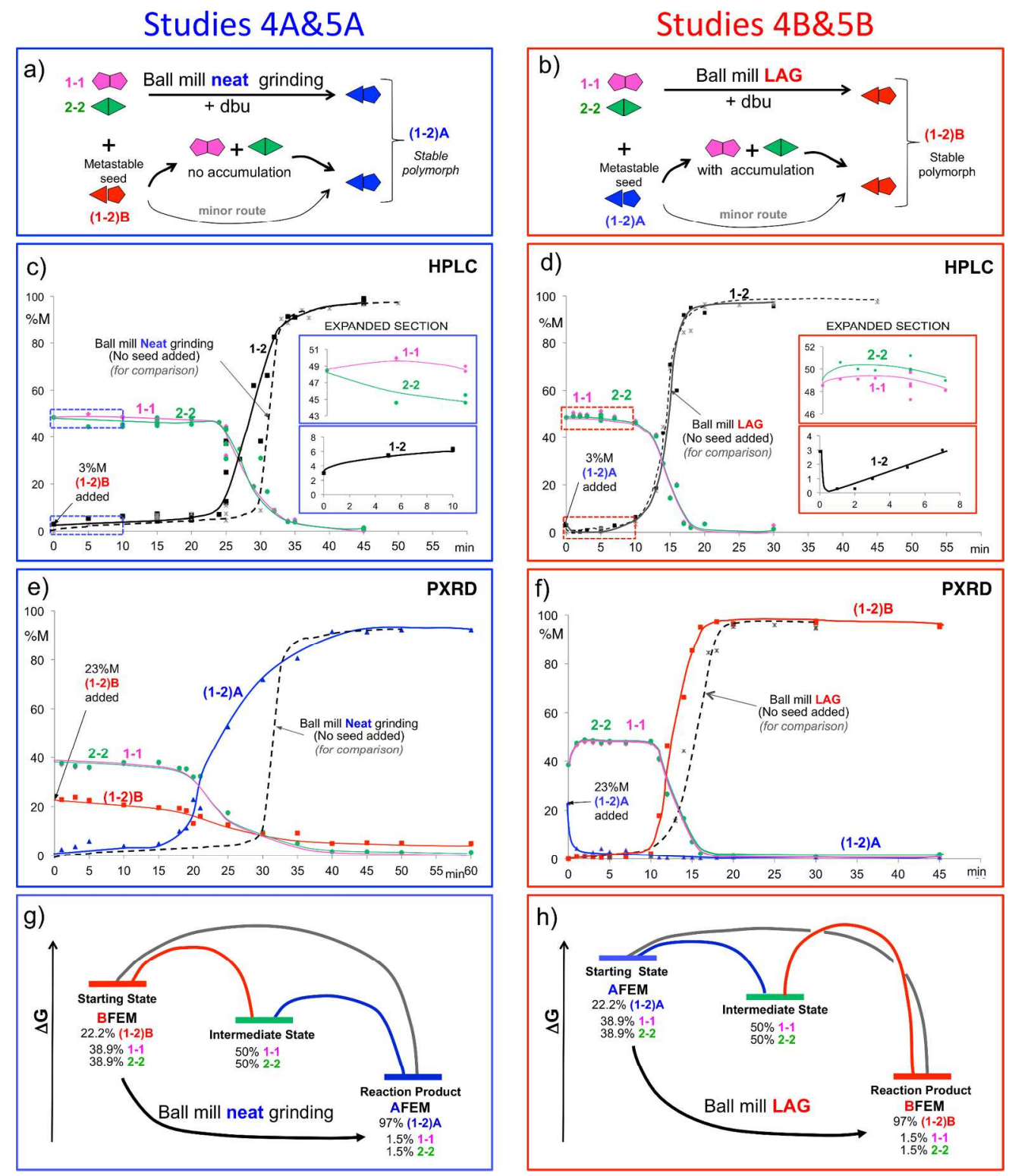

Figure 5 Solid state DCC studies reacting 1-1 and 2-2 in equimolar ratio seeded with the metastable polymorph of 1-2 in the presence of catalyst (dbu). Figures framed in blue on left represent ball mill neat grinding conditions ( $3 \% \mathrm{M}$ of seeds shown in $\mathrm{c}$ ); $23 \% \mathrm{M}$ of seeds shown in e). Figures framed in red on the right represent ball mill LAG conditions using $50 \mu \mathrm{L} \mathrm{MeCN} \mathrm{,} \mathrm{(} 3 \% \mathrm{M}$ of seeds shown in d); $23 \% \mathrm{M}$ of seeds shown in f). a) and b): reaction scheme. c), d), e), f): kinetic curves prepared as obtained from the Rietveld quantitative phase analysis. g) and $\mathrm{h}$ ): free energy diagrams. $177 \times 208 \mathrm{~mm}(300 \times 300$ DPI) 

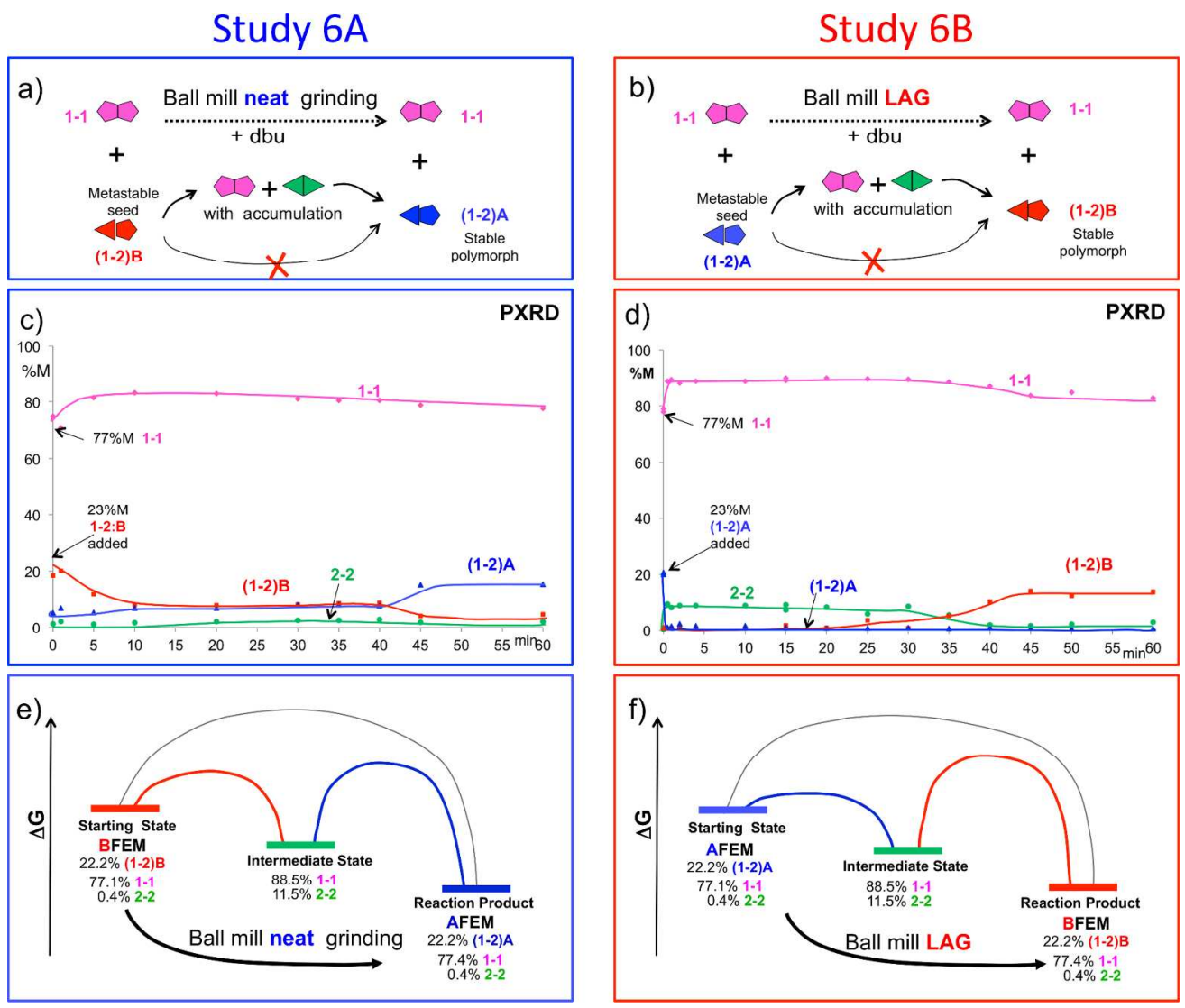

Figure 6 Solvent free DCC studies reacting $77 \% 1-1$ with $23 \%$ M of the metastable polymorph of $1-2$, in the presence of catalyst (dbu). Figures framed in blue on left represent ball mill neat grinding conditions. Figures framed in red on the right represent ball mill LAG conditions using $50 \mu \mathrm{L} \mathrm{MeCN.} \mathrm{a)} \mathrm{and} \mathrm{b):} \mathrm{reaction}$ scheme. c) and d): kinetic curves prepared as obtained from the Rietveld quantitative phase analysis. e) and f): free energy diagrams. $177 \times 150 \mathrm{~mm}(300 \times 300 \mathrm{DPI})$ 
Figure 7 Solvent free DCC studies reacting 77\%M 2-2 with 23\%M of the metastable polymorph of $1-2$, in the presence of catalyst (dbu). Figures framed in blue on left represent ball mill neat grinding conditions. Figures framed in red on the right represent ball mill LAG conditions using $50 \mu \mathrm{L} \mathrm{MeCN.} \mathrm{a)} \mathrm{and} \mathrm{b):} \mathrm{reaction}$ scheme. c) and d): kinetic curves prepared as obtained from the Rietveld quantitative phase analysis. e) and f): free energy diagrams.

$177 \times 149 \mathrm{~mm}(300 \times 300 \mathrm{DPI})$
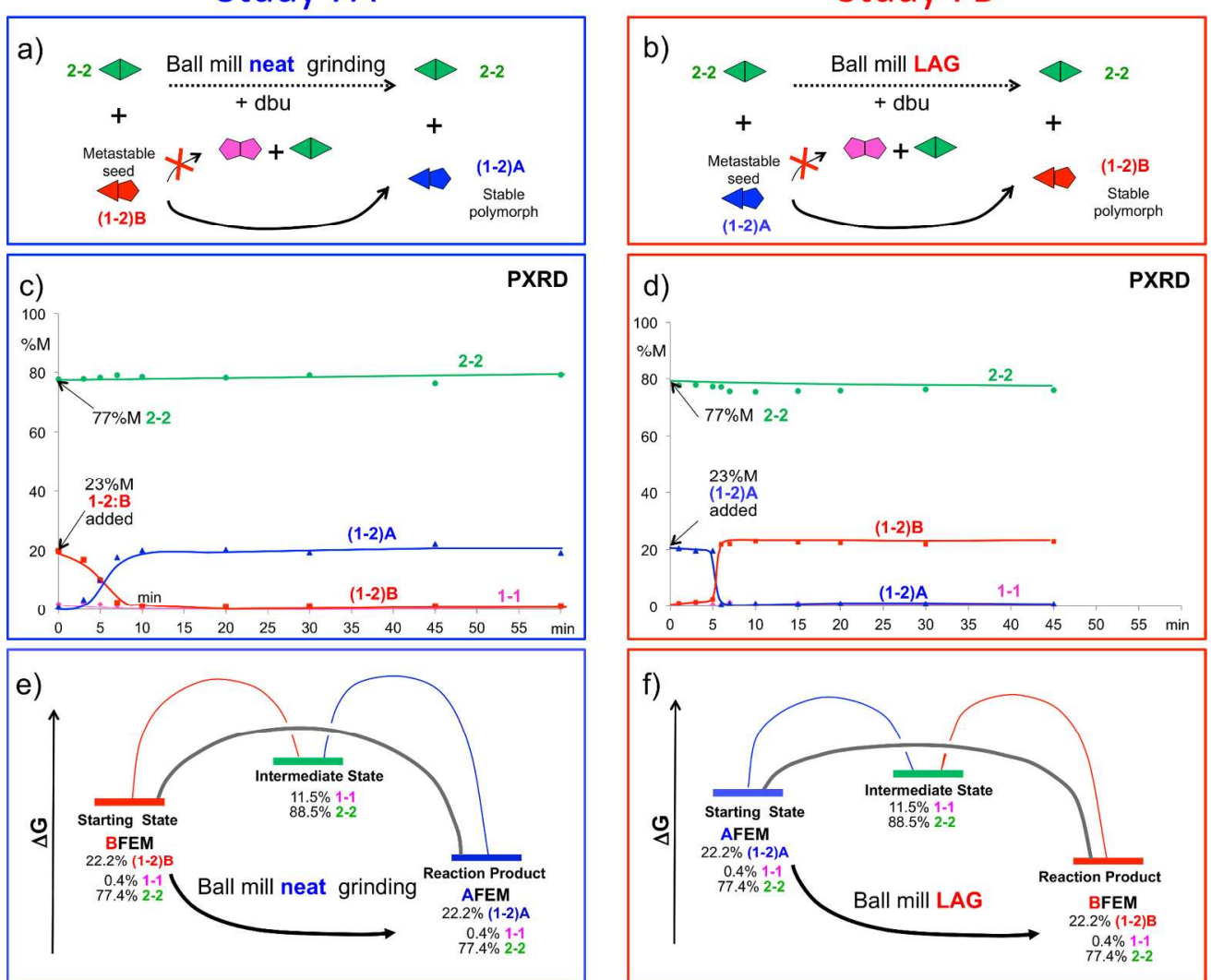


\section{Solid-State Dynamic Covalent Chemistry}

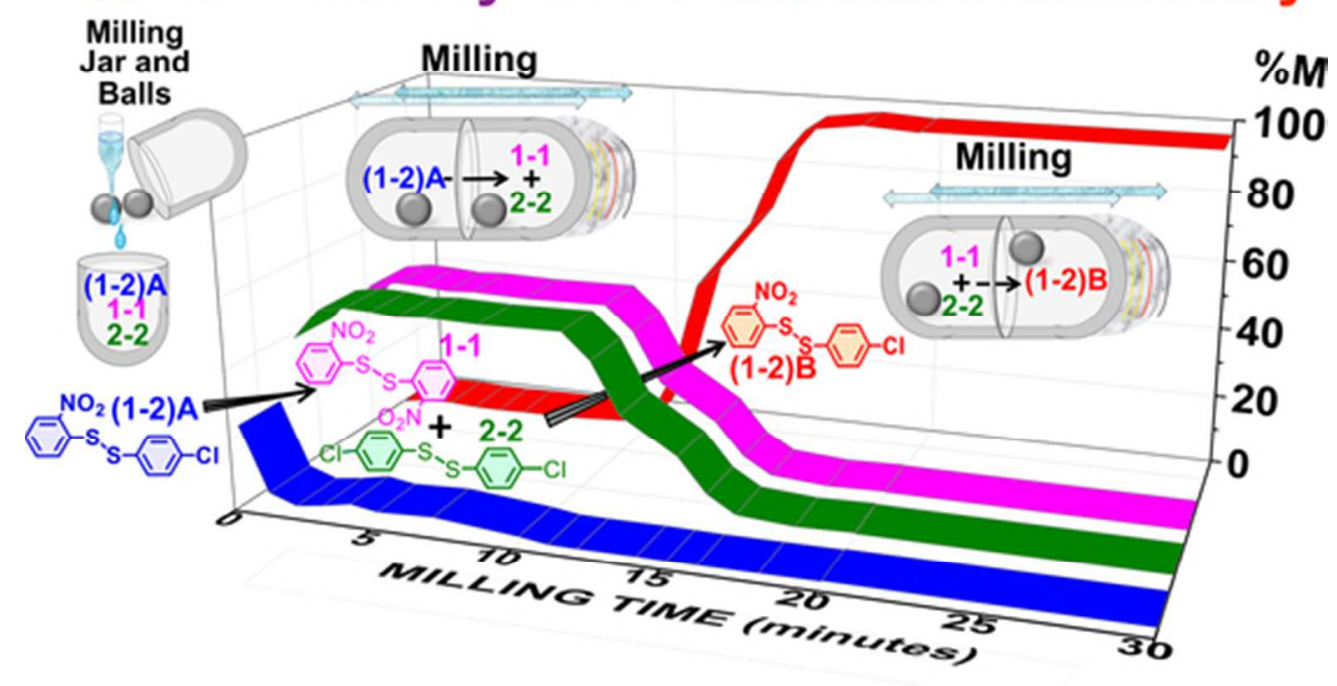

$47 \times 26 \mathrm{~mm}(300 \times 300 \mathrm{DPI})$ 


\section{Introduction}

Using both ball mill neat grinding and ball mill liquid assisted grinding (LAG), we demonstrate here the rich and unexpected behavior of a simple dynamic covalent chemistry (DCC) system, focussing on three remarkable observations: (i) the system exhibits reversible intercon-

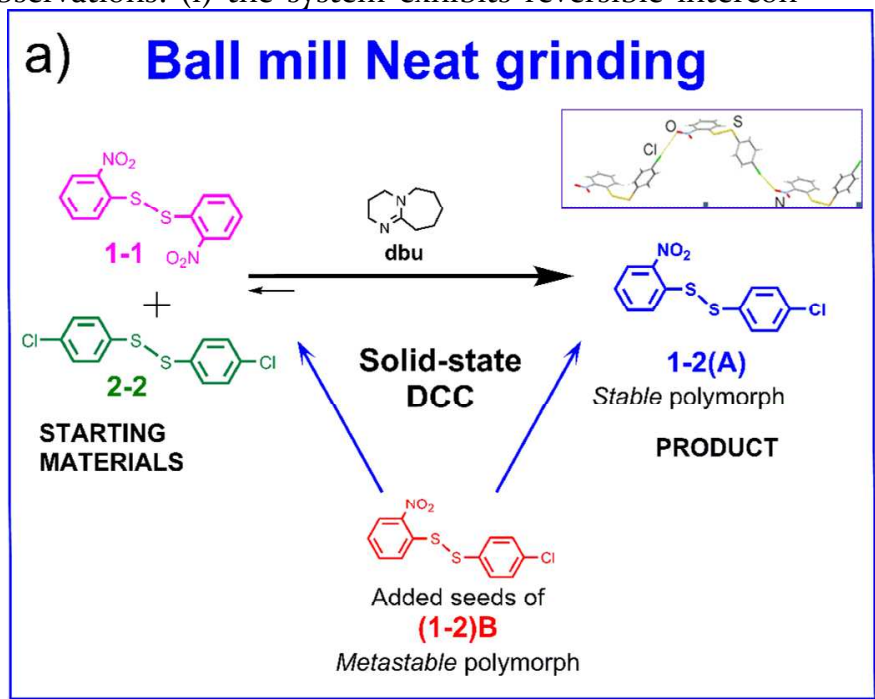

version of polymorphs of a disulfide heterodimer under thermodynamic control; (ii) in the presence of catalyst, polymorph interconversion involves sequential covalent reactions with observable covalent intermediates; (iii) one of the intermediates facilitates the covalent chemistry.

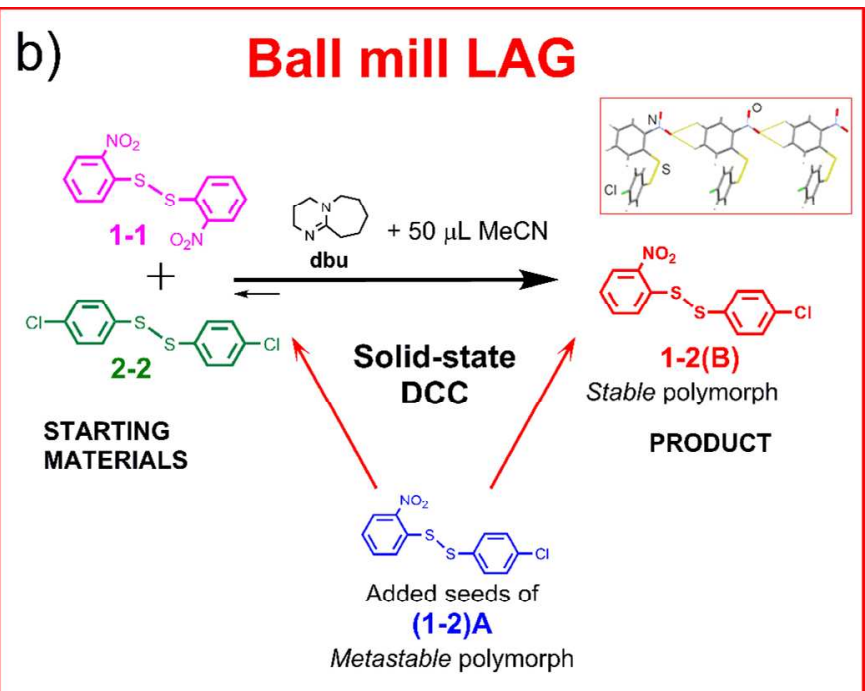

Figure 1 Solid state DCC reaction through ball mill grinding: (a) under neat and (b) under LAG conditions. From the solid state DCC reaction of the homodimers (CCDC ${ }^{1}$ codes ODNPDSoz and DCPHDS for $\mathbf{1 - 1}$ and $\mathbf{2 - 2}$ respectively) only the relevant stable polymorph of the heterodimer crystallizes. When seeds of the metastable polymorph of the heterodimer are introduced in the grinding system two simultaneous and competitive pathways are possible: a direct polymorph interconversion (route to the right) or a sequential transformation from (1-2)A to homodimers to (1-2)B (route to the left) under ball mill neat grinding conditions, or vice versa under ball mill LAG conditions. Details of (1-2)A (CCDC code FUQLIMo1) and (1-2)B (CCDC code FUQLIM) have been previously reported. ${ }^{2}$

We conclude that the outcome of these ball mill grinding reactions is driven by thermodynamics associated with nanoparticulate surface solvation. More importantly, we believe this interpretation to be applicable to many other ball mill grinding reactions, not necessarily involv- ing covalent chemistry. The system under study is illustrated in Figure 1.

Since this work is effectively the first detailed study of DCC in mechanochemical grinding (other than our pre- 
liminary report $)^{2}$ we first provide some background on these two previously separate fields.

\subsection{Dynamic Covalent Chemistry (DCC)}

DCC provides an approach to the discovery of complex architectures and receptors that may be inaccessible or unimaginable by rational design. ${ }^{3}$ It also has potential applications in a wide range of chemical and biological problems that involve binding equilibria in chemistry ${ }^{4}$ and biology ${ }^{3 f, 5}$. The members of a dynamic combinatorial library (DCL) are molecules that form in a combinatorial way by linking building blocks together through reversible covalent bonds that are dynamic, being continuously broken and reformed. The concentration of each library member is dictated by its relative free energy, so any phenomenon that can affect the stability of one or more DCL members will affect the concentration of all the library members in the DCL and therefore the overall DCL composition. For example, the addition of a template which selectively binds non-covalently to a specific library member amplifies the amount of this particular member at the expense of other less successful molecules. ${ }^{3 c}$ The dynamic equilibrium in DCL is easily demonstrated by the establishment of a new equilibrium in response to any perturbing stimulus. Many reversible reactions have been explored to date in $\mathrm{DCC}^{3 \mathrm{f}, 6}$ including the base-catalysed disulfide exchange used in this work; adding acid quenches the exchange, and freezes the composition for analysis. $^{2}$

In this report, we extend the study of DCC from the traditional dilute solution to the solid state. Not only does this abolish the need for substantial quantities of solvents, but crystal stability ${ }^{2}$ can act as a new driving force for establishing the position of equilibrium.

\subsection{Mechanochemisty induced by ball mill grinding}

Mechanochemistry $^{\S}$ is the field of chemical reactions induced by mechanical energy; this can involve reagents in any aggregate state (solid, liquid or even gas), though typically it refers to fully solid state processes. ${ }^{8}$ The term mechanochemistry embraces a broad range of areas, the mechanical energy required to activate the chemical reaction being provided by ultra-sound, ${ }^{9}$ (Balkenende, 2014 \#702\} an atomic force microscope (AFM), ${ }^{10}$ manual and mechanical grinding, " vortex grinding, ${ }^{12}$ or even simple mechanical forces, such as gripping with tweezers or puncture by a needle ${ }^{9 \mathrm{~b}}$. While the mechanochemistry of inorganic solids ${ }^{13}$ and metal complexes ${ }^{14}$ is a well established field, developments have been taking place more recently in organic and organometallic ${ }^{15}$ chemistry.

Organic reactions explored in manual or mechanical ball mill grinding ${ }^{16}$ include the formation of disulfides

\footnotetext{
$\S$ The term mechanochemistry is also used for a variety of different processes which happen in solution, including DCC related phenomena. $^{7}$
}

from thiols, ${ }^{17}$ disulfide exchange ${ }^{2}$, imine formation, ${ }^{8 b, 16 c, 18}$ boronic ester formation, ${ }^{16 c, 18 a}$ hydrazone formation, ${ }^{8 b, 16 c}$ and a range of $\mathrm{C}-\mathrm{C}$ bond forming reactions such as carbonyl condensations ${ }^{8 \mathrm{~b}, 16 \mathrm{c}, 19}$ and pericyclic reactions $^{8 \mathrm{~b}, 16 \mathrm{a}, 16 \mathrm{c}, 20}$. This has opened the field for the mechanochemical synthesis of complex chemical architectures, ${ }^{15 \mathrm{~b}}$ such as metal coordinated cages, ${ }^{21}$ fully organic cages, ${ }^{18 a}$ rotaxanes ${ }^{22}$ and capsules ${ }^{19 e}$.

Much of the mechanochemistry literature has been generated using manual grinding with pestle and mortar, where the reaction system is open, i.e. the solvent can escape from the system and the supplied mechanical energy is neither constant nor measurable. Here we perform ball mill grinding using a mechanical mixer mill (also called vibratory mill), which allows for reproducible and controlled milling frequencies and times. ${ }^{110}$ The milling jars are closed systems that allow the achievement of thermodynamic equilibrium as has already been proposed in the field of metal alloys. ${ }^{23}$ Some authors consider milling to be a non-equilibrium environment, and refer to "pseudo-equilibria" or "equilibrium states of milling". 11a

Mechanical ball mill grinding can be performed neat (without added solvent) or solvent assisted (LAG): in the latter, very small amounts of added liquid can dramatically accelerate and even enable mechanochemical reactions between solids. ${ }^{116,24}$ As yet little is known about the mechanisms and the driving forces involved in the chemical syntheses and supramolecular reactions induced by ball mill grinding. In two recent publications, the formation of organic and metal-organic supramolecular compounds by ball mill grinding under LAG and neat conditions was monitored in-situ and in real time by X-ray diffractometry (XRD) at a synchrotron facility. ${ }^{25}$ The resulting kinetic reaction curves clearly show a terminal plateau that may be indicative of a thermodynamic equilibrium: the authors do not comment on the possible driving force of the reactions studied.

Crystallization from solution may be thermodynamically or kinetically driven, or a combination of both: the initial formation of nuclei promotes the exponential growth of a specific polymorph as indicated by a sigmoidal kinetic curve. ${ }^{26}$ In general, the kinetic curves for ball mill grinding reactions are observed to exhibit a sigmoidal shape, this being consistent with the initial formation of nuclei promoting the exponential growth of the product. $^{25,27}$

Ball mill grinding is preceded or accompanied by a crystal size reduction of the starting materials, often down to an amorphous intermediate phase. ${ }^{2-25,28}$ Whether this possible amorphous, and therefore non-diffracting, material includes more than one state or any crystal nuclei is not known. ${ }^{29}$

Whether the ball mill grinding process as a whole can be regarded as a purely solid state process is uncertain, even in the neat case, because of the difficulty in controlling or measuring the exact reaction conditions such as average and local pressure and temperature. ${ }^{13 \mathrm{~b}}$ Some authors propose that the heat generated in the course of a 
mechanochemical process can induce local melting of crystals, ${ }^{8 a}$ or melting at the interface between crystals, ${ }^{30}$ or formation of liquid eutectic intermediate phases, ${ }^{11,, 13 b, 28 b, 31}$ so that in such cases the reaction takes place in the liquid phase even though a solid product is ultimately produced. We previously investigated and excluded an eutectic based mechanism for the current system, ${ }^{2}$ but a discussion of these mechanistic aspects is beyond the scope of this paper. We will focus here on the relative energy minima of the ball mill grinding process as an approach to interpret our experimental results as a thermodynamic outcome. Indeed, we show below that after the reaction reaches completion, equilibrium is achieved, with a stable phase composition. ${ }^{25,32}$

Unlike crystallisation in solution or a slurry experiment, the ball mill grinding process leads to extremely small crystals whose size is hard to predict or even to estimate. One report of in-situ and in real time monitoring by XRD of a ball mill grinding reaction describes the crystal size in a ball mill grinding reaction to approach the order of tens of $\mathrm{nm}$, giving a very different surface to volume ratio (S/V) from microcrystals. ${ }^{25 a}$ Thus, while thermodynamics conventionally assumes surface effects to be negligible (i.e. infinite bulk structures as in the case of slurry experiments) this is not the case in continuously mechanically ground systems. ${ }^{8 a}$ These thermodynamic aspects are general, and must apply to any milling system, independent of the mechanisms involved in the chemical reaction.

Small crystallites have higher enthalpies and free energies than large crystals because of a positive surface energy. ${ }^{33}$ Reactions occur not in the whole bulk of the sample, but at the interfaces between the phases. ${ }^{8 a}$ The role of mechanical action is usually to provide mixing, decreasing particle size and generating fresh surface for the contact. ${ }^{8 a}$ In contact with a solvent as it happens in crystallisation experiments in solution or in ball mill grinding under LAG conditions, the particle surfaces are solvated. Solvated surfaces are not simply a sharp boundary, but have a finite depth that can extend up to one nanometer. ${ }^{34}$ Thus at high $\mathrm{S} / \mathrm{V}$ ratio as in the case of nanocrystals obtained by ball mill grinding, the contribution of the solvated surface to the free energy minimum of a given polymorph is significant. In the case of $\mathrm{ZnS}$ nanocrystals ( $3 \mathrm{~nm}$ in diameter) absorption and desorption of methanol were found to reversibly change the atomic arrangement of the bulk structure. ${ }^{35}$ Hence the free energy minima of different polymorphs at the nanoscale will depend on the energetics of the bulk structures, the $\mathrm{S} / \mathrm{V}$ ratio of the crystallites, and the extent of solvation of the surface of the crystallites. Therefore, the relative free energy of one polymorph versus another will depend on the solvent used in the case of ball mill LAG or in the lack of solvent in the case of ball mill neat grinding. ${ }^{36}$

\subsection{Solid state DCC}

The solid state DCC reaction shown in Figure 1 has been selected to utilise one of the simplest DCC systems available: the metathesis of two linear symmetric disulfide homodimers which can result only in the formation of a linear asymmetric disulfide heterodimer. What we learn from this simple solid state DCC reaction should then be relevant to more complex oligomeric DCC systems, including other reversible chemistries. In solution, the system leads to a statistical mixture of the two homodimers (25\% each) and the heterodimer (50\%). Using ball mill grinding, the thermodynamic outcome is dramatically biased towards the heterodimer (97\% yield) rather than homodimers (1.5\% each). ${ }^{2}$ We also demonstrated in the earlier work that solid state DCC can lead to two different polymorphs of the same product depending on whether the ball mill grinding reaction is performed under neat or under LAG conditions. ${ }^{2}$ This is a new aspect of DCC only possible in the solid state.

\subsection{Background to the present Study}

In our previous paper we demonstrated that the solid state DCC reaction in Figure 1 was under thermodynamic control. The two homodimers, 2-nitrophenyl disulfide [(2$\left.\left.\mathrm{NO}_{2} \mathrm{PhS}\right)_{2}\right]$ and 4 -chlorophenyl disulfide $\left[(4-\mathrm{ClPhS})_{2}\right]$, are here referred to as 1-1 and 2-2, respectively, the corresponding heterodimer is referred to as $\mathbf{1 - 2}$, and the base catalyst is 1,8-diazabicyclo[5-4.o] undec-7-ene (dbu).

Two separate tests proved that the constant composition of the product observed on reaching the plateau was thermodynamically determined: a) the same final composition was obtained regardless of the composition of the starting state, provided that the equimolar stoichiometry of the added homodimers 1-1 and 2-2, was respected; b) we proved that the plateau was not a kinetic sink, by demonstrating its dynamic nature. ${ }^{2}$ The chemical composition of the reaction mixture was monitored using high performance liquid chromatography (HPLC) and determined the polymorphic form of the quantitative product at equilibrium by powder X-ray diffraction (PXRD). Brief investigations using solid state NMR and solid state FTIR did not reveal any useful quantitative information, so we have not included them.

We also reported in our previous work that solid state DCC can lead to different polymorphs of the heterodimer depending on whether the experiments correspond to ball mill neat grinding conditions, forming a polymorph of 1-2 referred to here as (1-2)A, or ball mill LAG conditions, forming a different polymorph of 1-2 referred to here as (1-2)B. ${ }^{2}$ It was implied that both polymorphs (1-2)A and (1-2)B represent the final equilibrium product of the reaction under ball mill neat and ball mill LAG conditions, respectively, but no proof was provided. Indeed the very idea that adding one drop of solvent to a milling jar could switch the thermodynamic equilibrium from one polymorph to the other is challenging. Thus the thermodynamic aspects of these milling systems required the further investigations reported below.

In the present work we have added the solid state composition obtained by Rietveld refinement of PXRD data collected throughout the grinding process, giving us the opportunity of identifying and quantifying which, and how much, of each polymorph is formed during the ball 
mill grinding reaction. All samples were also analysed by HPLC. Performing kinetic studies of seeding experiments provides us with a powerful tool to elucidate the reaction pathway of solid state DCC reactions by monitoring the solid state composition as grinding proceeds.

Equipped with these tools, we now explore whether the heterodimer polymorph crystallization is determined by kinetics or thermodynamics, what are the intermediate products, if any, and how mechanochemical crystallization by ball mill grinding proceeds.

We show here that the experimental milling conditions of the DCC reaction, i.e. the presence or absence of a small quantity of solvent, which allows for solvated surfaces of the nanosized crystals, determine the polymorph selection at equilibrium (see Section 3.1): under ball mill neat grinding conditions the DCC reaction exclusively yields polymorph (1-2)A, which is thus the stable polymorph under these conditions (Figure 1a); when the reaction is carried out under ball mill LAG conditions, (1-2)B is formed, which is the stable polymorph under ball mill LAG conditions (Figure $\mathrm{ib}$ ). If polymorph (1-2)B is added to the equimolar mixture of the two homodimers under ball mill neat grinding conditions (Figure 1a) then it is fully transformed to (1-2)A; (1-2)B is therefore the metastable polymorph under ball mill neat grinding conditions. Similarly, polymorph (1-2)A is metastable under ball mill LAG conditions and rapidly transforms to (1-2)B (Figure $1 b$ ). Polymorph transformations are crucial in the pharmaceutical industry and generally in any field where the final product is used and commercialized as a solid phase. ${ }^{37}$

\section{EXPERIMENTAL DETAILS}

We present here 14 kinetic studies, which were designed to explore the different kinetic and thermodynamic features of our solid state DCC reaction, both under ball mill neat grinding conditions (i.e. in the absence of solvent) in studies $A_{1}$ to $A_{7}$, and under the corresponding ball mill LAG conditions (i.e. with $50 \mu \mathrm{L}$ of acetonitrile added to $200 \mathrm{mg}$ of powder in the grinding jar) in studies B1 to $\mathrm{B}_{7}$.

The kinetic curves presented here were prepared from PXRD or HPLC data obtained from individual experiments, each experiment corresponding to a single grinding time. This approach avoids disrupting the delicate equilibrium achieved during grinding between the vapor, the liquid and the solid components in the enclosed chamber of the snap-closed grinding jar.

Samples of the components of the homodimers 1-1, 2-2 and the added seeds of the polymorph of $\mathbf{1 - 2}$, as required, were accurately weighed, resulting in a typical loading of $200 \mathrm{mg}$. The solid powders were individually added to a 14.5 mL stainless steel grinding jar together with two 7 $\mathrm{mm}$ ID stainless steel ball bearings. After the addition of $2 \mu \mathrm{L}(2 \% \mathrm{M})$ of catalyst ( $\mathrm{dbu})$ into the jar, nothing else was added for ball mill neat grinding while $50 \mu \mathrm{L}$ acetonitrile was added for ball mill LAG experiments. The jars were snap closed and grinding was performed at $30 \mathrm{~Hz}$ on a MM40o Retsch automated grinder (see Figure SI 39 and SI 40) for the specified period of time. After completion of the grinding period, the jar was immediately opened and the contents analyzed; the results obtained as \%M concentration versus grinding time were used to construct the corresponding kinetic profiles.

The number of grinding experiments and grinding times for a given study depended on how many points were required to represent, with good definition, the sigmoidal segment of the kinetic curve and ascertain that the system had finally reached a plateau. Indeed, the rigorous experimental procedures detailed in the Supplementary Information (SI) were found to be crucial for reproducibility. The solid state composition of the samples, reported here as \%M, was determined by Rietveld refinements from PXRD data. The chemical composition of the sample was obtained by HPLC analysis. While the PXRD analysis is not as sensitive or accurate (estimated accuracy $\pm 3 \% \mathrm{M}$ absolute and estimated sensitivity: limit of detection (LOD) as $3 \% \mathrm{M}$ ) as HPLC (estimated sensitivity $0.1 \% \mathrm{M}$ relative to main component), it supplies the phase composition. Therefore all further discussion regarding kinetic profiles will be based on the Rietveld refinements of the PXRD data. The agreement between PXRD and HPLC analysis was found to be excellent (See SI). More details about the analytical methods can be found in the SI.

\section{RESULTS AND DISCUSSION}

To help the reader, kinetic curves for ball mill neat grinding studies are shown framed in blue, while ball mill LAG experiments are shown framed in red for Figures 2-7. No fitting was performed and the kinetic curves are only a guide to the eye. Each time point in these kinetic plots corresponds to a single grinding experiment. The findings of these studies are summarized at the top of Figures 2-7 in the form of reaction schemes for each kinetic study. To appreciate the thermodynamic aspects and to recognize the relative predominance of the competing kinetic pathways, we summarize these relative free energy minimum (FEM) states for the starting state, intermediate state and reaction product at the bottom of each figure in the form of a free energy level diagram. These levels and the corresponding energy barriers between the starting state and intermediate state and reaction product have been inferred from our kinetic studies. Analysis of these kinetic data has allowed us to distinguish alternative reaction pathways, preferred as well as unlikely pathways, for each grinding study.

\subsection{Unseeded solid state DCC experiments}

We will start this discussion with unseeded grinding studies. These solid state DCC experiments were performed by grinding equimolar amounts of the homodimers, $\mathbf{1 - 1}$ and 2-2, in the presence of catalyst (2\% $\mathrm{Mbu}$ ). Figure 2 shows the findings of the ball mill neat grinding experiments (Study $1 \mathrm{~A}$ ) on the left and ball mill LAG experiments with $50 \mu \mathrm{L} \mathrm{MeCN}$ (Study $1 \mathrm{~B}$ ) on the right. 
Study $1 A$
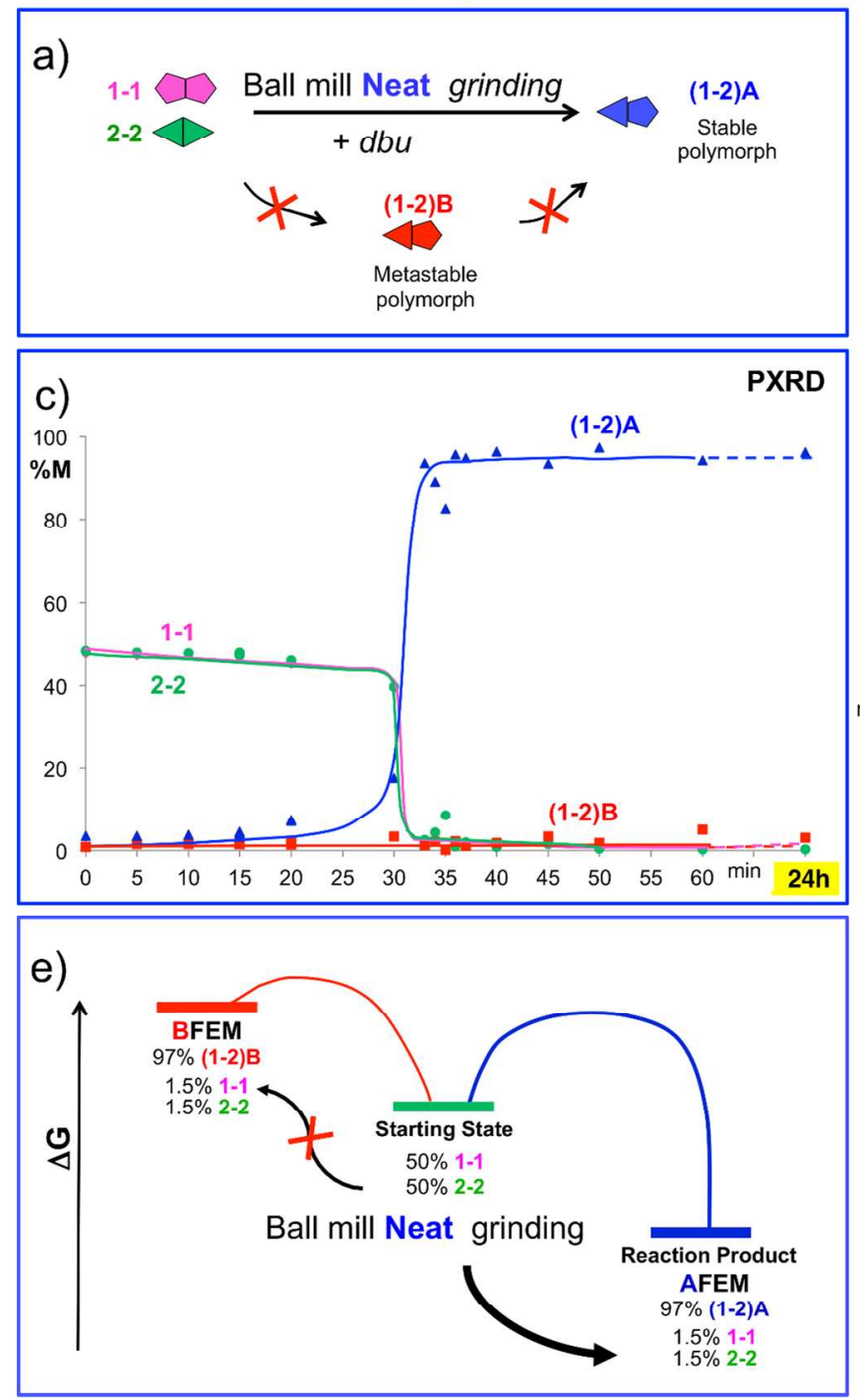

Study 1B
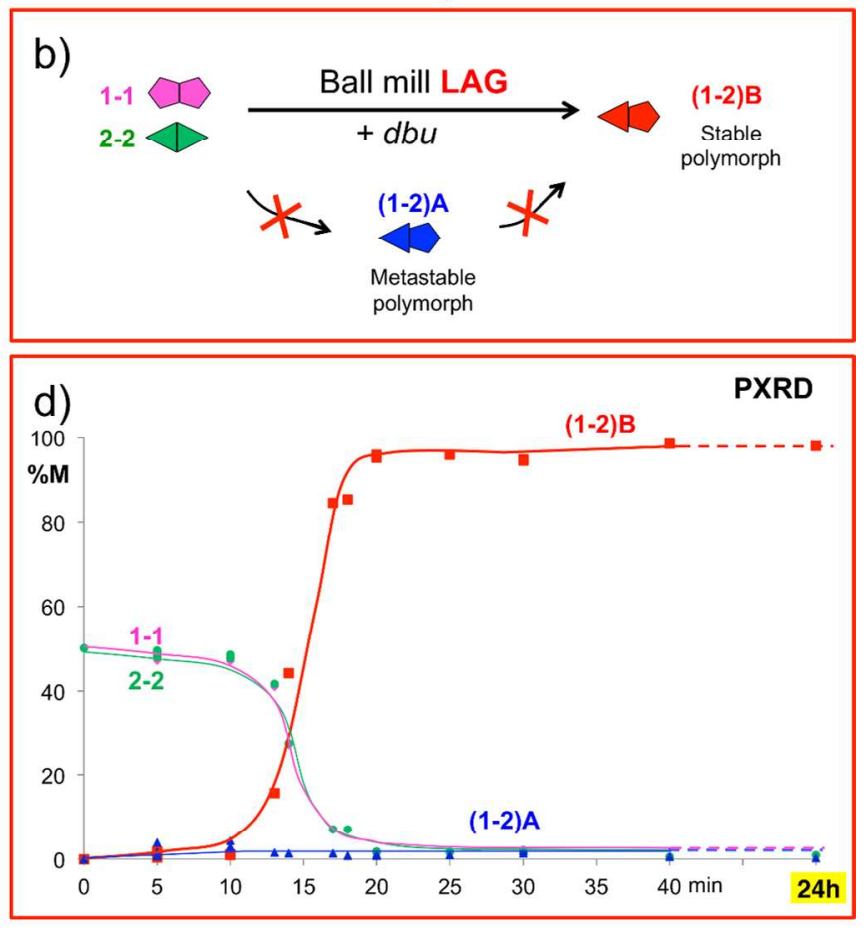

f)

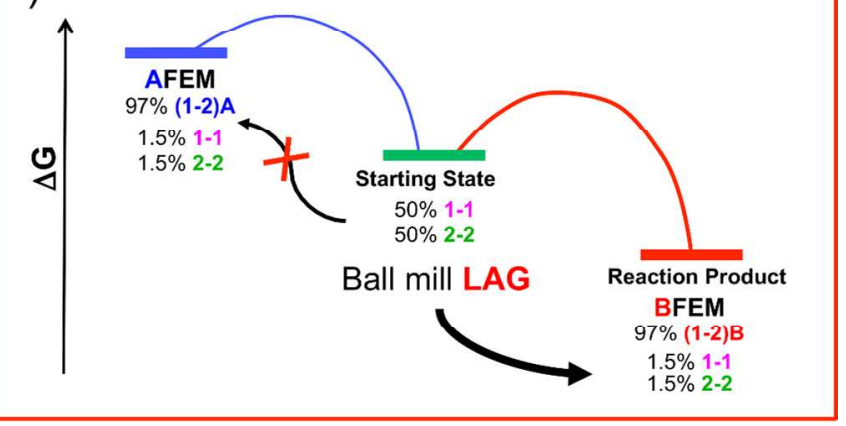

Figure 2 Solid state DCC studies reacting 1-1 and 2-2 in equimolar ratio (no added seeds of $\mathbf{1 - 2}$ ) in the presence of catalyst (dbu). Figures framed in blue on the left represent ball mill neat grinding conditions. Figures framed in red on the right represent ball mill LAG conditions using $50 \mu \mathrm{L} \mathrm{MeCN}$. a) and b): reaction scheme. c) and d): kinetic curves prepared as obtained from the Rietveld quantitative phase analysis. e) and f): free energy diagrams.

The solid state DCC reaction reached equilibrium, always resulting in quantitative formation of the stable polymorph of 1-2, its composition being maintained for extended grinding periods (i.e. 24 hours). The metastable polymorph of 1-2 was never observed at any time point of the grinding process. These unseeded reactions exhibited a long delay before a significant concentration $(7 \% \mathrm{M})$ of the stable polymorph of $\mathbf{1 - 2}$ was observed: $\mathbf{2 5}$ minutes for ball mill neat grinding studies (Figure $2 \mathrm{c}$ ) and 10 minutes for ball mill LAG studies (Figure 2d), showing that the ball mill LAG process is faster than the ball mill neat one. It is known that very small amounts of added liquid can dramatically accelerate mechanochemical reactions be- tween solids. In other words, given a mechanochemical reaction, ball mill LAG is generally faster that ball mill neat grinding. ${ }^{\text {lb }}$ However in our case ball mill LAG and ball mill neat grinding lead to two different polymorphs, (1-2)B and (1-2)A respectively, so their reaction rates cannot be directly compared. ${ }^{1 \mathrm{lb}, 38}$

Both ball mill neat grinding and ball mill LAG reactions exhibited a nucleation phase (around 5 minutes) and a sharp transition before reaching a constant plateau.

Any change in the phase composition affects the position of the free energy minima (FEM) levels and their corresponding energy barriers. For brevity, we designate 
AFEM as the FEM containing (1-2)A and BFEM as the FEM containing (1-2)B. The composition of the FEM level of the starting state for Studies $1 \mathrm{~A}$ and $1 \mathrm{~B}$ was equimolar amounts of 1-1 and 2-2.

Under ball mill neat grinding conditions (Figure 2e) the equilibrium is represented by the AFEM containing (12)A, which is the stable polymorph and the only polymorph of 1-2 observed in the ball mill neat grinding reaction. Under ball mill LAG conditions (Figure $2 \mathrm{f}$ ) the equilibrium corresponds to BFEM containing (1-2)B, which is the stable polymorph and the only polymorph of 1-2 observed in the ball mill LAG reaction. As the kinetic curves for ball mill neat grinding (Figure 2c) are slower that those for ball mill LAG (Figure 2d), the energy barrier between the starting state and the reaction product (AFEM) for ball mill neat grinding (Figure 2e) must be higher than that between the starting state and the reaction product (BFEM) for ball mill LAG (Figure $2 \mathrm{f}$ ).

\subsection{Solid state DCC reaction seeded with the stable polymorph of the heterodimer}

Figure 3 displays the results from grinding experiments seeded with $3 \% \mathrm{M}$ of the stable polymorph of 1-2 to an equimolar amount of 1-1 and 2-2 in the presence of catalyst $(2 \% \mathrm{M} d b u)$. The ball mill neat grinding experiments (Study 2A) and the ball mill LAG experiments with $50 \mu \mathrm{L}$ $\mathrm{MeCN}$ (Study $2 \mathrm{~B}$ ) are on the left and right sides of the figure respectively. These studies showed a decrease in the lag time by 10 to 12 minutes compared to unseeded studies, maintaining the shape of the sigmoidal segment, as shown in Figure $3 \mathrm{c}$ for ball mill neat grinding studies and in Figure $3 \mathrm{~d}$ for ball mill LAG studies.

The Rietveld refinement of PXRD data showed that only the stable polymorph was formed under these experimental conditions, but faster than for the corresponding unseeded studies. The interpretation of these data in the form of free energy level diagrams is shown in Figure ze for ball mill neat grinding studies and Figure $3 \mathrm{f}$ for ball mill LAG studies: the increase in the rate of reaction must be predominantly a consequence of a significant reduction of the energy barriers between the starting state and the reaction product.

\subsection{Direct polymorph interconversion in the absence of catalyst}

Direct polymorph interconversion from the metastable to the stable polymorph requires only a supramolecular rearrangement of the crystal lattices of (1-2)B $\rightarrow(\mathbf{1 - 2}) \mathbf{A}$ for ball mill neat grinding studies and (1-2)A $\rightarrow(\mathbf{1 - 2}) \mathbf{B}$ for ball mill LAG studies. Such direct transformation in milling experiments has been reported before in other systems. ${ }^{39}$ We here explored these direct polymorph interconversions in Study 3-A under ball mill neat grinding conditions and in Study 3-B under ball mill LAG conditions; their outcomes are shown on the left side and on the right side of Figure 4, respectively. In these experiments $23 \% \mathrm{M}$ of the metastable polymorph of 1-2 was added to $77 \% \mathrm{M}$ of equimolar amounts of 1-1 and 2-2 homodimers in the absence of $\mathrm{dbu}$ to prevent any DCC reaction from taking place.

As expected, the $77 \% \mathrm{M}$ concentration of equimolar amounts of 1-1 and 2-2 remained unreacted. Under ball mill neat grinding conditions, the $23 \% \mathrm{M}$ concentration of the metastable polymorph (1-2)B was fully transformed into the stable polymorph (1-2)A in around 10 minutes, the kinetic curve presenting a shallow sigmoidal kinetic segment, the conversion starting soon after grinding was initiated (Figure 4c). Similar kinetic curves were observed under ball mill conditions, where $(\mathbf{1 - 2}) \mathbf{A} \rightarrow(\mathbf{1 - 2}) \mathbf{B}$ in around 10 minutes too (Figure $4 \mathrm{~d}$ ). In summary, direct polymorph interconversion rapidly transformed the metastable polymorph to the stable one in very little time. 
Study $2 A$
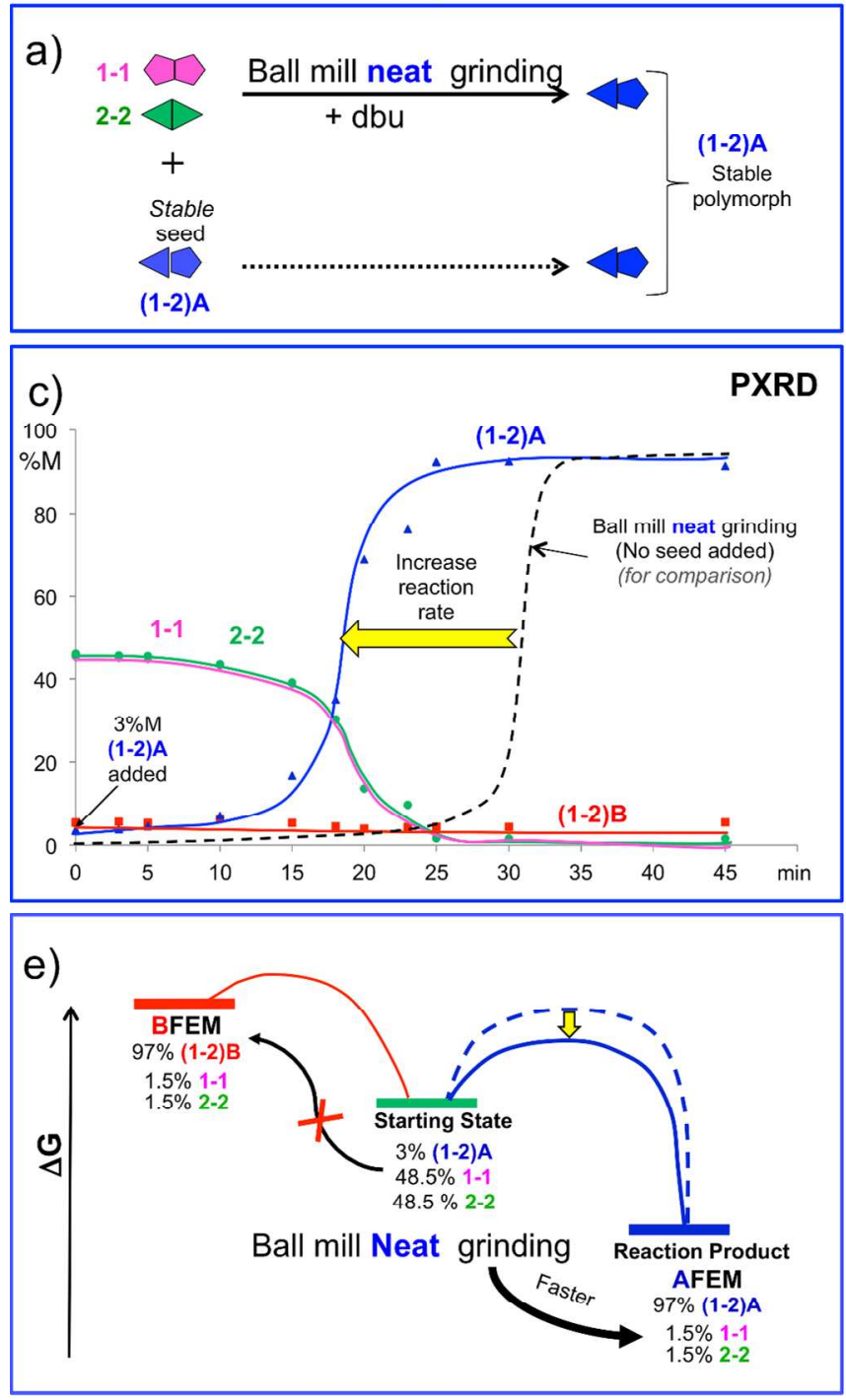

Study 2B
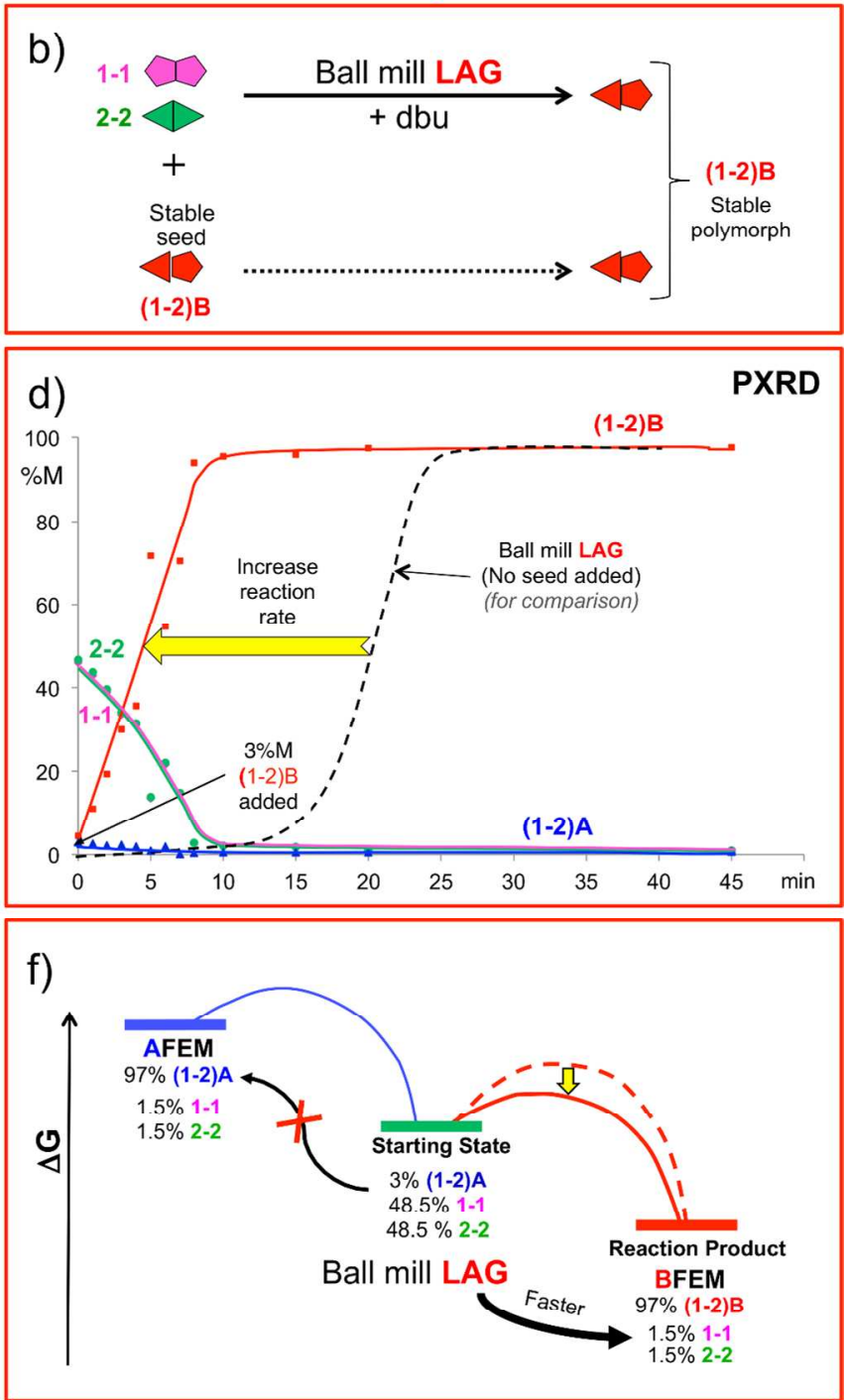

Figure 3 Solid state DCC studies reacting 1-1 and 2-2 in equimolar ratio seeded with $3 \% \mathrm{M}$ of the stable polymorph of 1-2 in the presence of catalyst (dbu). Figures framed in blue on left represent ball mill neat grinding conditions. Figures framed in red on the right represent ball mill LAG conditions using $50 \mu \mathrm{L} \mathrm{MeCN}$. a) and b): reaction scheme. c) and d): kinetic curves prepared as obtained from the Rietveld quantitative phase analysis. e) and f): free energy diagrams. 
Study $3 A$

Study 3B
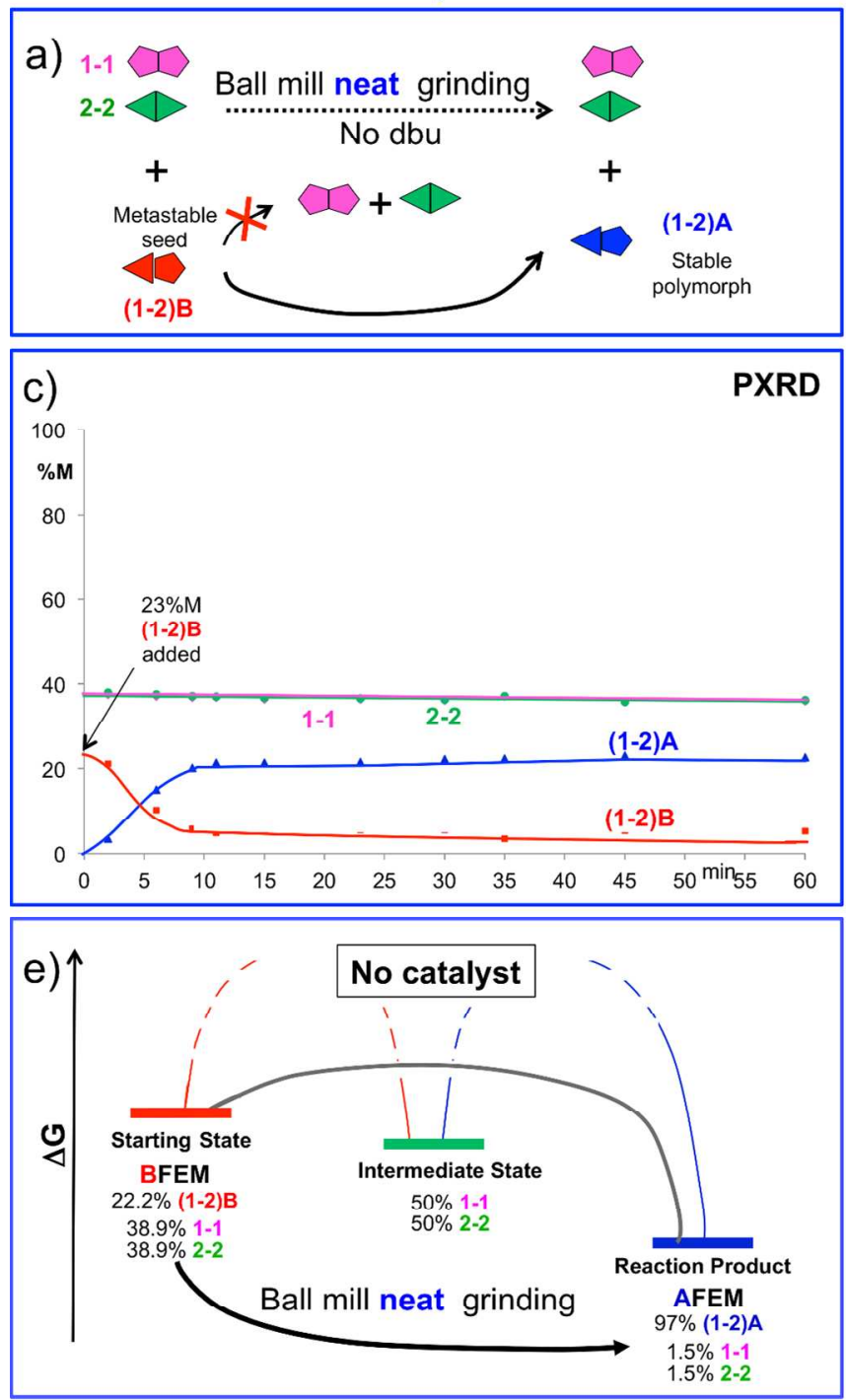

Figure 4 Solid state DCC studies reacting 1-1 and 2-2 in equimolar ratio seeded with $23 \% \mathrm{M}$ of the metastable polymorph of 1-2, in the absence of catalyst (dbu). Figures framed in blue on left represent ball mill neat grinding conditions. Figures framed in red on the right represent ball mill LAG conditions using $50 \mu \mathrm{L} \mathrm{MeCN}$. a) and b): reaction scheme. $c$ ) and d): kinetic curves prepared as obtained from the Rietveld quantitative phase analysis. e) and f): free energy diagrams.

\subsection{Solid state DCC reaction seeded with the meta- stable polymorph of the heterodimer}

Unexpected phenomena were observed in studies 4 and 5 where seeds of the metastable polymorph of 1-2 were added to equimolar amounts of 1-1 and 2-2 in the presence of dbu catalyst $(2 \% \mathrm{M})$. These experiments were initially performed at $3 \% \mathrm{M}$ concentration of the added seeds (Figure 5c,d, Study 4), the composition of which could only be analyzed by HPLC, $3 \% \mathrm{M}$ being the limit of detec-
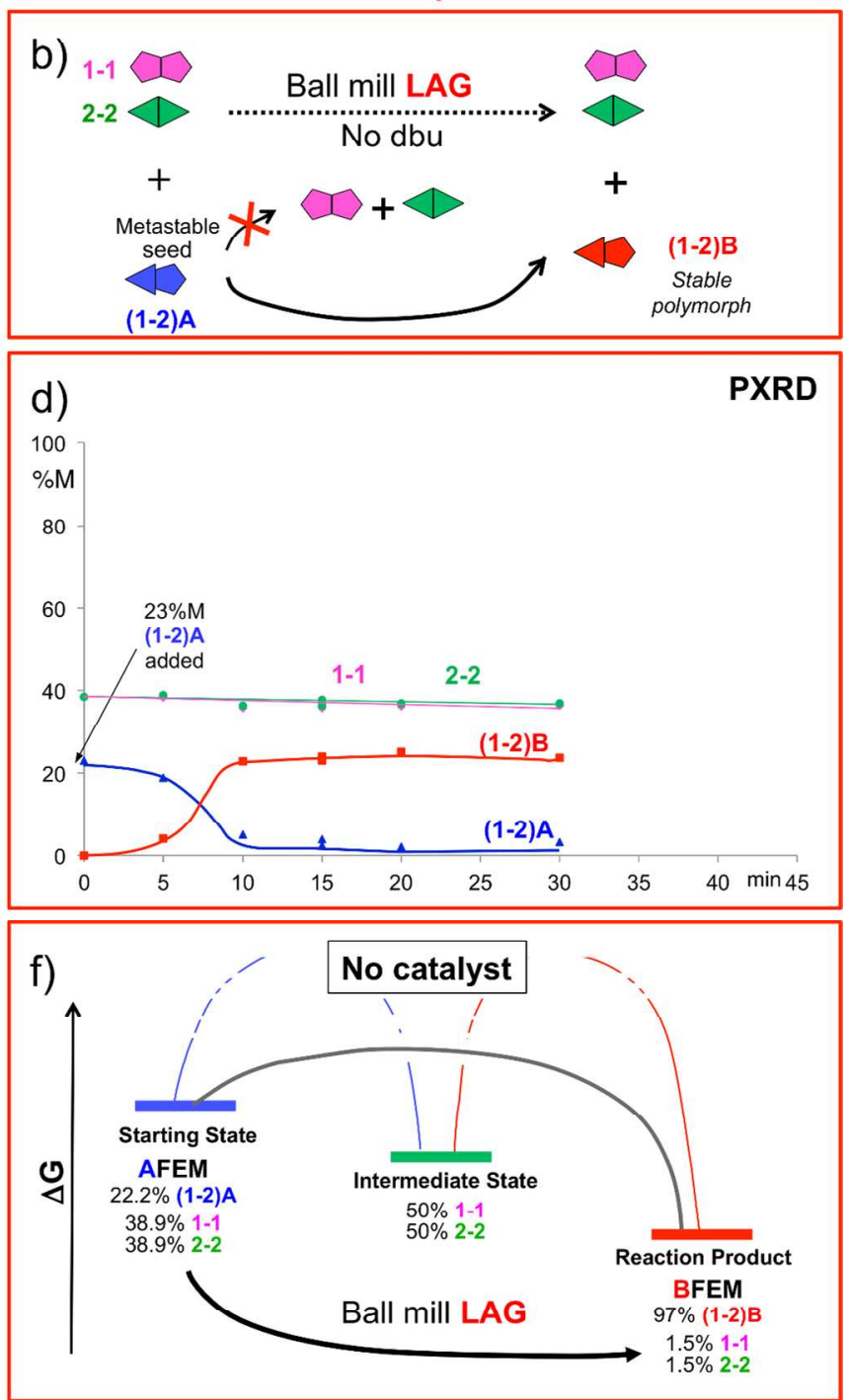

tion of the PXRD method. A higher concentration of seeds (23\%M, Figure 5e,f, Study 5) was required to monitor the solid state composition by PXRD.

\subsubsection{Ball mill LAG}

The kinetic curves for the ball mill LAG case in Study 5$B$ illustrated in Figure $5 \mathrm{f}$ present an unexpected observation. 


\section{Studies 4A\&5A}
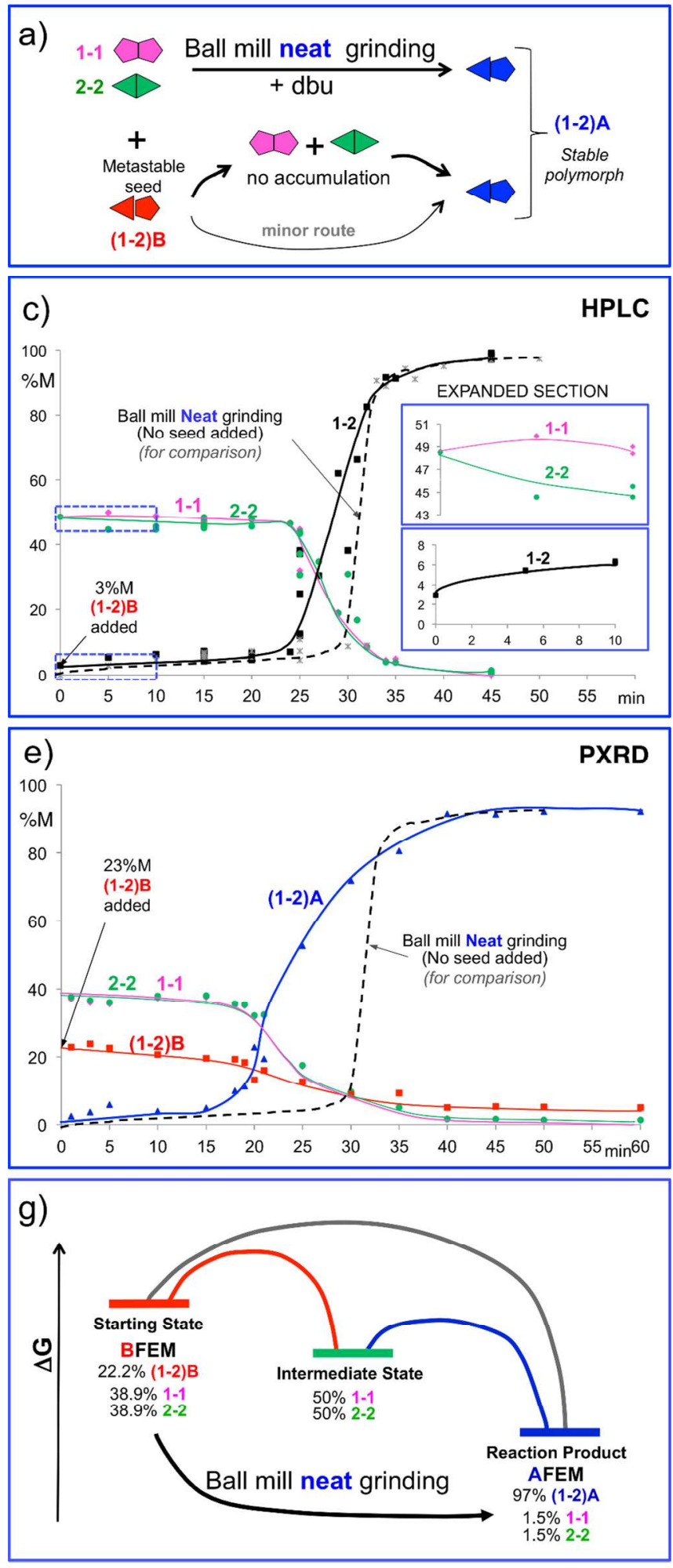

Studies 4B\&5B
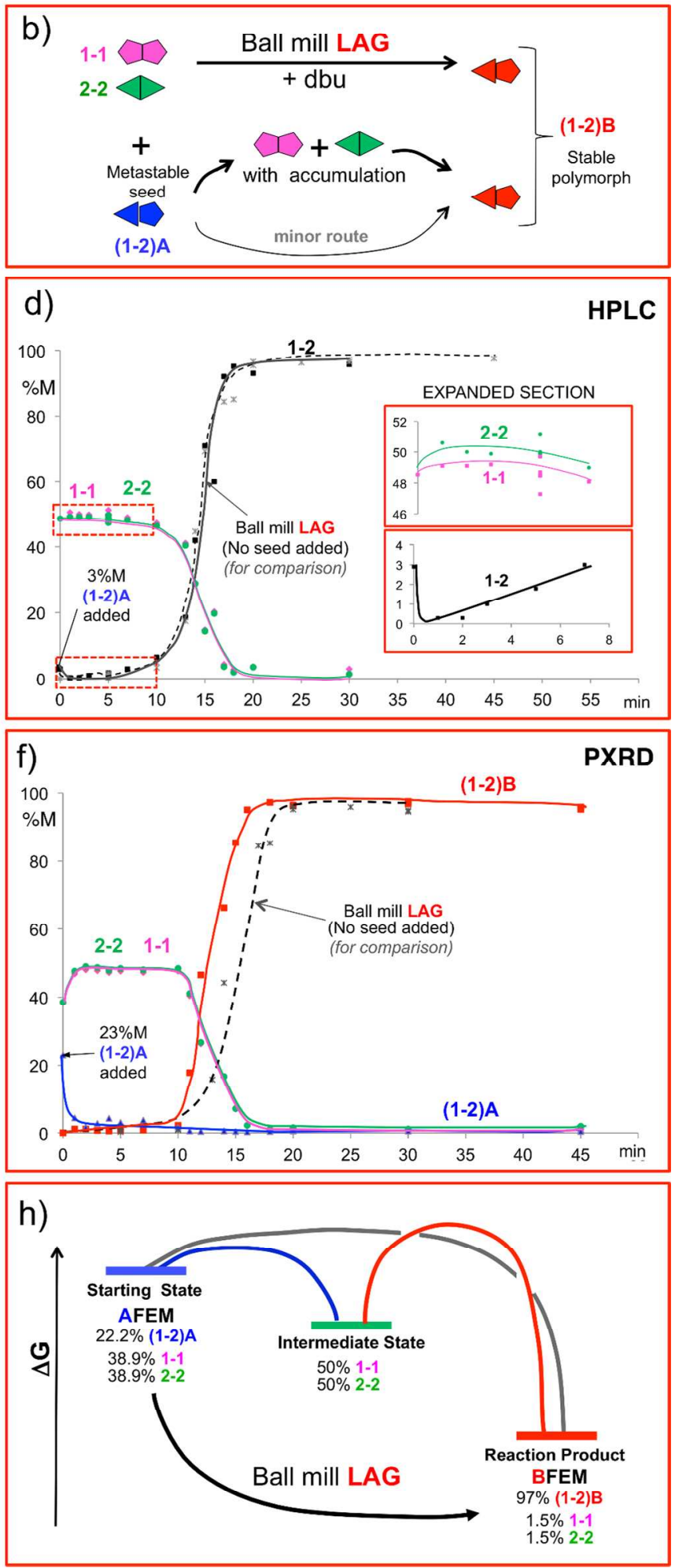

Figure 5 Solid state DCC studies reacting 1-1 and 2-2 in equimolar ratio seeded with the metastable polymorph of 1-2 in the presence of catalyst (dbu). Figures framed in blue on left represent ball mill neat grinding conditions ( $\% \mathrm{M}$ of seeds shown in c); $23 \% \mathrm{M}$ of seeds shown in e). Figures framed in red on the right represent ball mill LAG conditions using $50 \mu \mathrm{L} \mathrm{MeCN},(3 \% \mathrm{M}$ of seeds shown in d); $23 \% \mathrm{M}$ of seeds shown in f). a) and b): reaction scheme. c), d), e), f): kinetic curves prepared as obtained from the Rietveld quantitative phase analysis. g) and h): free energy diagrams.

The rapid disappearance of (1-2)A from the initial concentration of $23 \% \mathrm{M}$ down to $3-5 \% \mathrm{M}$ within the first mi- nute of ball mill grinding was accompanied by a simultaneous increase of the concentration of 1-1 and 2-2 from 
the initial concentration of $37.5 \% \mathrm{M}$ up to $47-48 \% \mathrm{M}$. In other words, the reduced concentration of (1-2)A exactly matched the corresponding increase in the concentration of 1-1 and 2-2. After the first minute and for the next 9 minutes, the concentration of 1-1 and 2-2 stayed constant at $48 \% \mathrm{M}$ while the concentration of (1-2)A was around 3$5 \% \mathrm{M}$. The freshly formed 1-1 and 2-2 were therefore the covalent intermediates in the first step reaction $[(\mathbf{1 - 2}) \mathbf{A} \rightarrow$ $\mathbf{1 - 1}+\mathbf{2 - 2}]$ of a sequential pathway, where (1-2)A is transformed to (1-2)B. This process involves bond breaking and bond forming of the reversible disulfide bond. This is the first time that a purely covalent reaction has been reported to be involved in a polymorph interconversion that we are aware of. ${ }^{40}$

The interpretation of this sequential mechanism in the form of free energy level diagrams is shown in Figure 5 h. Since we observed an accumulation of the covalent intermediates for over 10 minutes, the second step of the sequential mechanism $[\mathbf{1 - 1}+\mathbf{2 - 2} \rightarrow(\mathbf{1 - 2}) \mathbf{B}]$ must be the rate determining step (RDS).

The kinetics in Study ${ }_{5} \mathrm{~B}$ were found to be significantly faster (3-4 minutes) when compared to corresponding unseeded experiments (Study $1 \mathrm{~B}$ ). This result seems counterintuitive. If the two-step sequential transformation were to be the only operative pathway in Study ${ }_{5} \mathrm{~B}$, it should have resulted in a delay of the kinetics. This slight increase in the reaction rate with respect to Study $1 B$ could indicate that an alternative minor but faster pathway (the direct polymorph interconversion) is acting competitively and simultaneously in Study $5^{\mathrm{B}}$ to the sequential transformation as depicted in Figure $5 \mathrm{~h}$. We suggest that the residual fraction of (1-2)A not immediately consumed by the sequential pathway, was transformed into (1-2)B within a few minutes by the direct interconversion pathway, these freshly created seeds of (1-2)B acting as template and thus increasing the DCC reaction rate.

\subsubsection{Ball mill neat grinding}

Unlike under ball mill LAG conditions in Study $5^{B}$ (Figure $5 \mathrm{f}$ ), the kinetic curves of Study $5 \mathrm{~A}$ under ball mill neat grinding conditions (Figure 5e) showed no signs of accumulation of covalent intermediates. Despite this observation, we propose that the transformation of the metastable (1-2)B to the stable polymorph (1-2)A under ball mill neat grinding conditions also proceeds through two competitive and simultaneous pathways, the sequential mechanism being the predominant path (Figure $5 \mathrm{~g}$ ).

In the ball mill neat grinding case the sequential path has to be inferred from the reaction rate and the kinetic curve in Figure 5e which shows a shallow sigmoidal shape. This shallow curve is different from the sharp sigmoidal segments for the corresponding unseeded experiments (Figure 2c, Study $1 \mathrm{~A}$ ) or the corresponding studies seeded with the stable polymorph (Figure 3c, Study 2A). Had the direct polymorph interconversion been the predominant or exclusive pathway, we should have seen a sharp nucleation phase as in Study $1 \mathrm{~A}$ and $2 \mathrm{~A}$.

The delay in the polymorph interconversion and the shallow kinetic curve can be explained by the transformation happening competitively and simultaneously through a direct polymorph interconversion and a sequential mechanism, the latter being the predominant one. Since there is no accumulation of the covalent intermediate, the first step of the sequential process $[(\mathbf{1 - 2}) \mathbf{B} \rightarrow \mathbf{1 - 1}+\mathbf{2 - 2}]$ must be the RDS: as soon as the covalent intermediates 1-1 and 2-2 are formed in the RDS step 1, they are immediately consumed in the lower energy barrier step 2 to form (1-2)A.

\subsection{Effect of the nature of the homodimers on the competition between the sequential and the di- rect polymorph transformation}

We were interested in understanding if the presence of the two homodimers, 1-1 and 2-2, had any effect on the polymorph interconversion reaction. We therefore designed kinetic studies so that $23 \% \mathrm{M}$ seeds of the metastable polymorph of 1-2 were added to either $77 \% \mathrm{M}$ of 1-1 only (Figure 6 , Study 6 ) or to $77 \% \mathrm{M}$ of $\mathbf{2 - 2}$ only (Figure 7 , Study 7 ) in the presence of catalyst. 


\section{Study 6A}
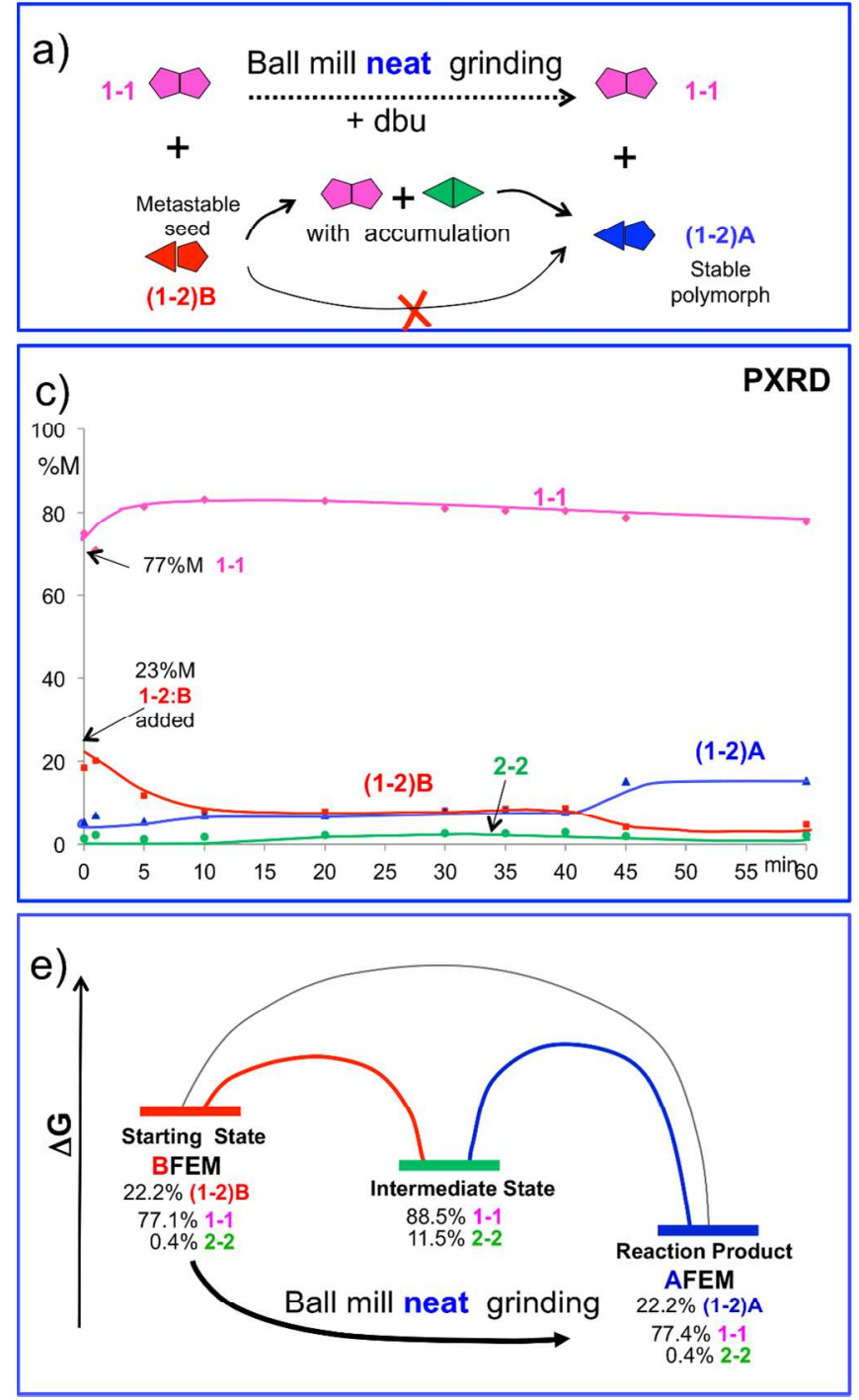

Study 6B
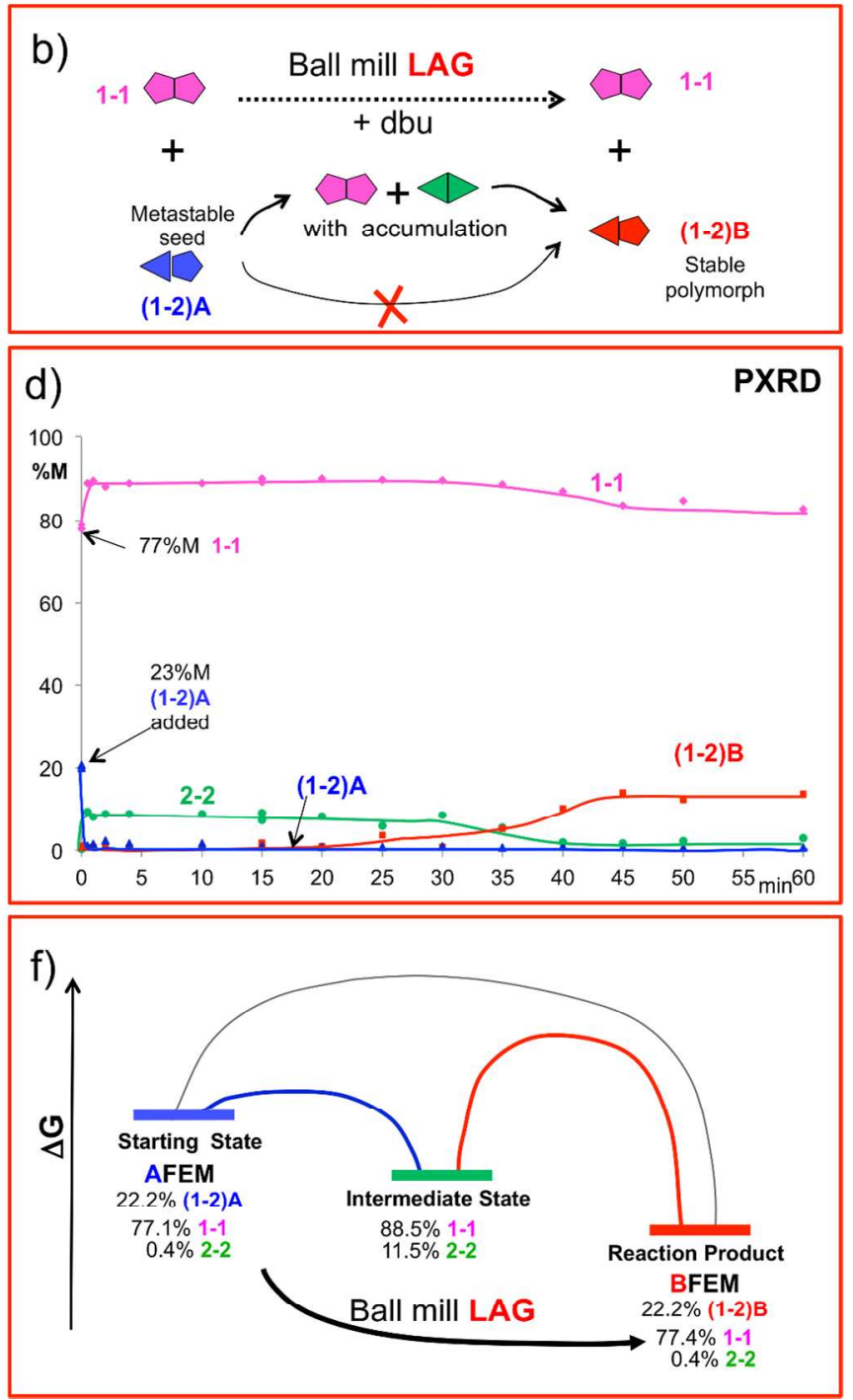

Figure 6 Solvent free DCC studies reacting $77 \%$ 1-1 with 23\%M of the metastable polymorph of 1-2, in the presence of catalyst (dbu). Figures framed in blue on left represent ball mill neat grinding conditions. Figures framed in red on the right represent ball mill LAG conditions using $50 \mu \mathrm{L} \mathrm{MeCN}$. a) and b): reaction scheme. c) and d): kinetic curves prepared as obtained from the Rietveld quantitative phase analysis. e) and f): free energy diagrams.

Adding metastable polymorph seeds just to 1-1 resulted in very similar kinetic curves for ball mill neat grinding (Figure 6c, Study 6A) and ball mill LAG studies (Figure $6 \mathrm{~d}$, Study $6 \mathrm{~B}$ ). Both graphs have the tell-tale signs of the sequential covalent route: immediate reduction of the metastable polymorph of $\mathbf{1 - 2}$ with simultaneous accumulation of 1-1 and 2-2 (Figure 6a,b). The accumulation time before conversion to the stable polymorph of 1-2 product molecule was now much longer when compared to Study ${ }_{5} \mathrm{~B}$. This result indicates that the direct polymorph interconversion does not occur to any significant extent in Study $6 \mathrm{~A}-\mathrm{B}$, and the two step reaction thus takes longer than an unseeded experiment. The free energy level in- terpretation of Study 6 is consistent with a significant stabilization of energy level of this intermediate state with respect to the starting state, both under ball mill neat grinding (Figure 6e) and under ball mill LAG (Figure 6f); this resulted in a lowering of the energy barriers for the sequential mechanism, while the energy barrier for the direct conversion was increased. Under these experimental conditions, the sequential mechanism was predominant or exclusive, the second step of the sequential mechanism being the RDS, with relative accumulation of 1-1 and 2-2. 
Study 7A
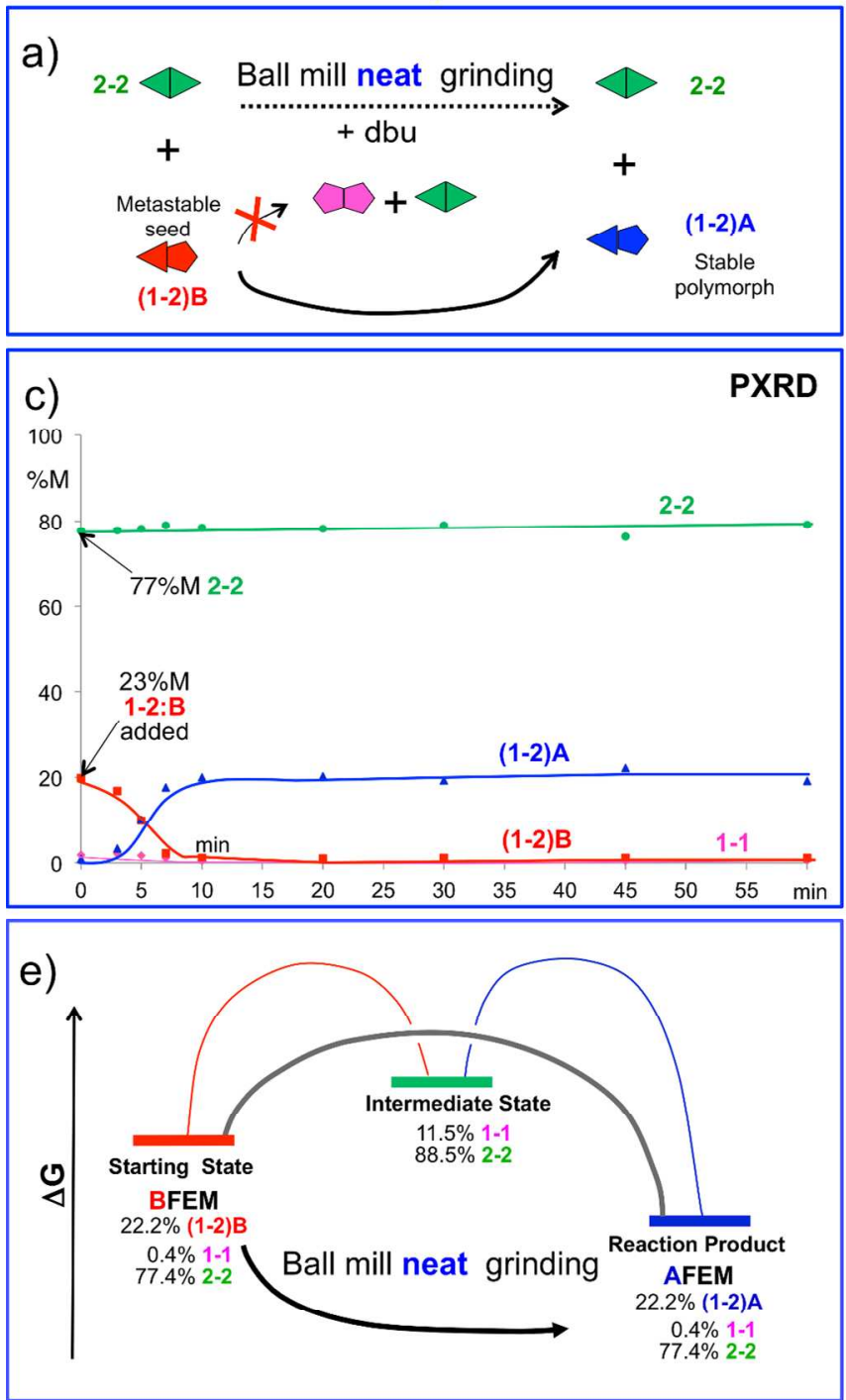

Study 7B
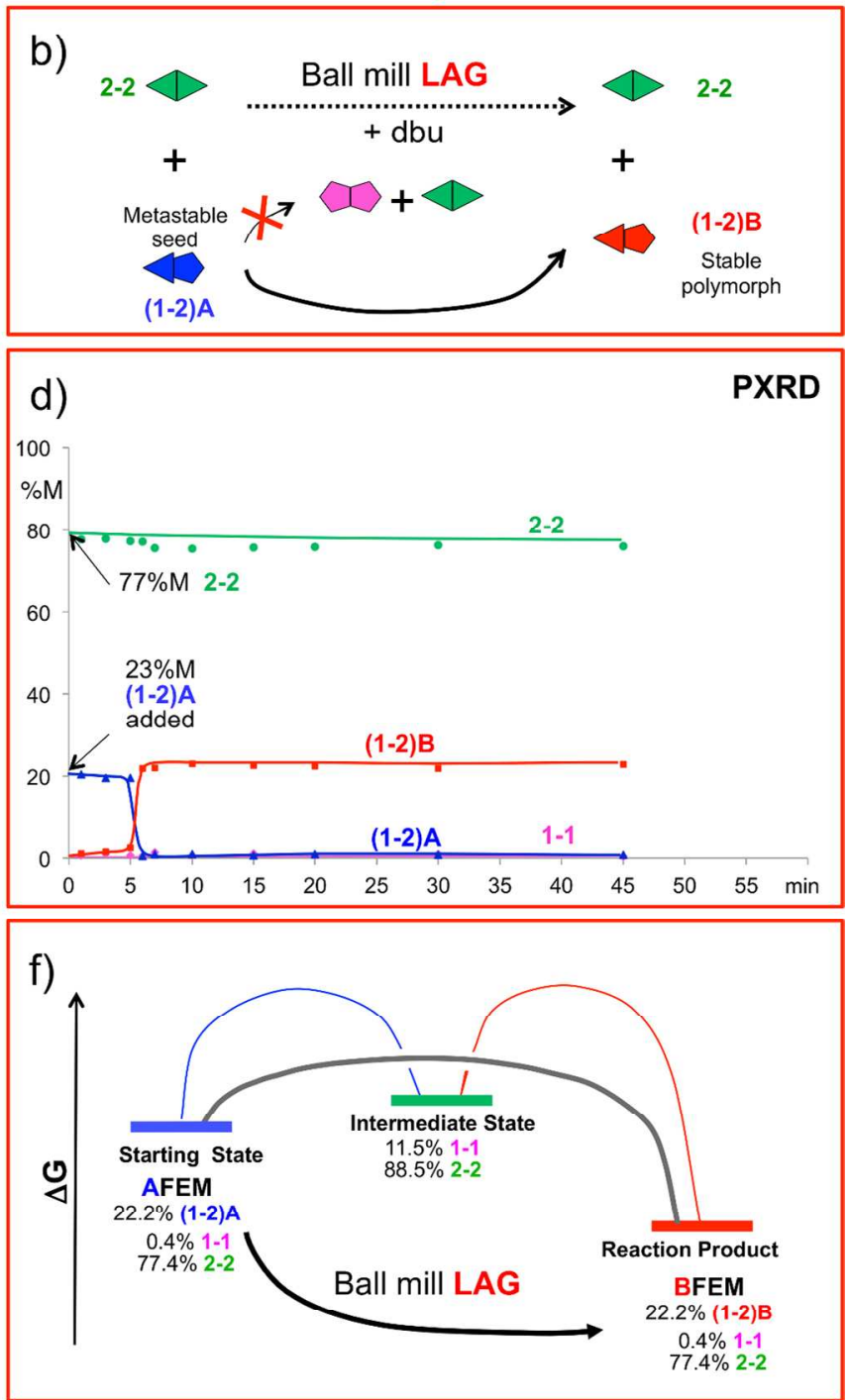

Figure 7 Solvent free DCC studies reacting $77 \% \mathrm{M}$ 2-2 with $23 \% \mathrm{M}$ of the metastable polymorph of $\mathbf{1 - 2}$, in the presence of catalyst $(\mathrm{dbu})$. Figures framed in blue on left represent ball mill neat grinding conditions. Figures framed in red on the right represent ball mill LAG conditions using $50 \mu \mathrm{L} \mathrm{MeCN}$. a) and b): reaction scheme. c) and d): kinetic curves prepared as obtained from the Rietveld quantitative phase analysis. e) and f): free energy diagrams.

In contrast, when the same seeds of the metastable polymorph of 1-2 were added to $77 \% \mathrm{M}$ of pure 2-2 (Figure 7), the direct transformation pathway was predominant or exclusive for both ball mill neat grinding (Figure 7c, Study $7 \mathrm{~A})$ and ball mill LAG (Figure $7 \mathrm{~d}$, Study $7 \mathrm{~B}$ ), and showed the same kinetic profile as those in Study $3 \mathrm{~A}$ (Figure $4 \mathrm{C}$ ) and Study $3^{B}$ (Figure $4 \mathrm{~d}$ ) performed in the absence of $\mathrm{dbu}$, where only the direct polymorph transformation could take place. The free energy level interpretation of Study 7 is consistent with a significant destabilization of energy level of this intermediate state with respect to the starting state, both under ball mill neat grinding (Figure 7e) and under ball mill LAG conditions (Figure 7f); this resulted in an increase of the energy barriers for the sequential mechanism, while the energy barrier for the direct conversion was decreased. Under these experimental conditions, the direct mechanism was predominant or exclusive.

"Seeding assisted" polymorphic transformation was recently reported for the covalent synthesis of imines by manual grinding, where the addition of seeds of a specific polymorph directed the selection of the polymorph formed. ${ }^{41}$ In contrast, for the solid state DCC system studied here, we have demonstrated that while seeding with the stable polymorph leads to an acceleration of the reaction (Figure 3), "seeding assisted" polymorphic transformation did not take place, i.e. seeding with the metastable polymorph resulted in its complete transformation to the stable polymorph (Figures 4, 5, 6 and 7). 


\section{Conclusions}

We have provided extensive experimental evidence that only the more stable of the two polymorphs of the heterodimer is exclusively formed in almost quantitative yield in our solid state dynamic covalent chemistry model reactions. No further change in the equilibrium composition was observed after up to 24 hours of continuous grinding. The experimental conditions, especially the absence of solvent for ball mill neat grinding or the presence of a few drops of acetonitrile for ball mill LAG, determines which polymorph of the product is formed on grinding. Under ball mill neat grinding conditions (1-2)A is the stable polymorph, and (1-2)B is the metastable one. Under ball mill LAG conditions (1-2)B is the stable polymorph, and (1-2)A is the metastable one. Therefore we have experimentally demonstrated that the identity of the stable and metastable polymorphs is reversed under ball mill neat grinding and ball mill LAG conditions. Predictably, the rate of reaction was increased when the material was seeded with the stable polymorph. The addition of seeds of the metastable polymorph leads to a rich and unexpected reaction path affecting the kinetics without changing the final phase composition at equilibrium: the metastable polymorph is always converted into the more stable one. In the absence of catalyst the seeds of the metastable polymorph were transformed into the more stable polymorph exclusively by direct polymorph interconversion, as no DCC chemical reaction can take place. In the presence of catalyst, this polymorph interconversion occurred by two simultaneous and competitive routes: a direct transformation and a sequential route, which is predominant. In the latter route, the first step is the conversion of the metastable polymorph of the heterodimer into its corresponding homodimers which thus are the covalent intermediates in this reversible reaction. This is the first time that a purely covalent bond breaking and reforming has been reported in the literature to be involved in a polymorph interconversion. Under ball mill LAG conditions the RDS is the second step, while under ball mill neat grinding conditions the RDS is the first step of the sequential route. Furthermore, we have proved that the presence of 2-2 homodimer promotes direct polymorph interconversion of the heterodimer, while the presence of 1-1 homodimer promotes the two-step sequential polymorph transformation, which exploits the reversible covalent disulfide bond. This work may be seen as an important step towards an understanding of the mechanisms and potential of solid state DCC.

The milling process reduces the crystallite size: we believe that the nanosized dimensions of the crystallites and/or the surface solvation free energy are key to understanding why the polymorph stability order is different in the presence or absence of the acetonitrile solvent. More importantly, this interpretation of the system may be general and apply to many other grinding processes.

\section{ASSOCIATED CONTENT}

Detailed procedure for the solid state DCC reaction, HPLC data, PXRD patterns, data and its corresponding Rieltveld refinement for each of the 14 studies and together with discussion of methodology used for the Rieltveld refinement. This material is available free of charge via the Internet at http://pubs.acs.org

\section{AUTHOR INFORMATION}

\section{Corresponding Author}

jkms@cam.ac.uk; amb84@cam.ac.uk,

\section{Author Contributions\#}

$¥$ These authors contributed equally.

\section{Funding Sources}

We are grateful to the EPSRC (AMB, JKMS and DJW) and ERC(DJW) for financial support.

Notes

The authors declare no competing financial interest.

\section{ACKNOWLEDGMENTS}

We thank T. Friščić for valuable discussions on the theory of ball mill grinding. We thank G. Day, P. Bygrave, V. Ruhle for discussion on the energy of crystal structures, Prof A. Gavezzotti, Dr L. Maini, M. Arhangelskis, Prof W. Jones, D. K. Bucar, B. Patel, J. Galcera, and Prof S. Redfern for help and scientific discussions, David Reid for performing solid state NMR and P. O'Meara, from Panalytical for technical support with the acquisition of PXRD spectra; We thank C. A. Bland for the mechanical design and P. Donnelly for the software design of the automation of the grinders and R. Nightingale and his team at the mechanical workshop of the Department of Chemistry for the manufacture of the jars and the Department of Earth Sciences for general support.

\section{ABBREVIATIONS}

DCC dynamic covalent chemistry; LAG liquid assisted grinding; HPLC high performance liquid chromatography PXRD powder X-ray diffraction; 1-1 2-nitrophenyl disulfide $\left[\left(2-\mathrm{NO}_{2} \mathrm{PhS}\right)_{2}\right] ; \mathbf{2 - 2} \quad$ 4-chlorophenyl disulfide $\left[(4-\mathrm{ClPhS})_{2}\right]$; dbu 1,8-diazabicyclo[5.4.0] undec-7-ene; 1-2 2-nitrophenyl-4chlorophenyl disulfide $\left(2-\mathrm{NO}_{2} \mathrm{PhSSPh}-4 \mathrm{Cl}\right) ;(\mathbf{1 - 2}) \mathrm{A}$ polymorph of 1-2 prepared under ball mill neat grinding conditions; (1-2)B polymorph of 1-2 prepared under ball mill liquid assisted grinding conditions; AFEM free energy minimum of (1-2)A in the presence of 1-1 and 2-2; BFEM free energy minimum of (1-2)B in the presence of $\mathbf{1 - 1}$ and 2-2; RDS rate determining step

\section{REFERENCES}

(1) Allen, F. H. Acta Crystallographica, Section B: Structural Science 2002, $B_{5} 8,380$.

(2) Belenguer, A. M.; Friscic, T.; Day, G. M.; Sanders, J. K. M. Chem. Sci. 2011, 2, 696.

(3) (a)Lehn, J.-M.; Eliseev, A. V. Science 2001, 291, 2331; (b)Ludlow, R. F.; Otto, S. Chem. Soc. Rev. 2oo8, 37, 101; (c)Cougnon, F. B. L.; Sanders, J. K. M. Acc. Chem. Res. 2011, 45, 2211; $\quad$ (d)Otto, S. Acc. Chem. Res. 2012, 45, 2200; $\quad$ (e)Li, J.; Nowak, P.; Otto, S. J. Am. Chem. Soc. 2013, 135, 9222; (f)Herrmann, A. Chem. Soc. Rev. 2014, 43, 1899 .

(4) (a)Belowich, M. E.; Stoddart, J. F. Chem. Soc. Rev. 2012, 41, 2003; (b)Feng, X.; Ding, X.; Jiang, D. Chem. Soc. Rev. 
2012, 41, 6010

(c)Herrmann, A. Chem. Eur. J. 2012 18, 8568; (d)Bilbeisi, R. A.; Olsen, J.-C.; Charbonnière, L. J.; Trabolsi, A. Inorg. Chim. Acta. 2014, 417, 79.

(5) (a)Greaney, M. F.; Bhat, V. T. In Dynamic Combinatorial Chemistry; John Wiley \& Sons, Inc.: 2009, p 43;

(b)Durai, C. R. S.; Harding, M. M. Aust. J. Chem. 2o11, 64, 671.

(6) Jin, Y.; Yu, C.; Denman, R. J.; Zhang, W. Chem. Soc. Rev. 2013, 42, 6634 .

(7) Carnall, J. M. A.; Waudby, C. A.; Belenguer, A. M.; Stuart, M. C. A.; Peyralans, J. J. P.; Otto, S. Science 2010, 327, 1502.

(8) (a)Boldyreva, E. Chem. Soc. Rev. 2013, 42, 7719; (b)Kaupp, G. Top. Curr. Chem. 2005, 254, 95.

(9) (a)Cravotto, G.; Gaudino, E. C.; Cintas, P. Chem. Soc. Rev. 2013, 42, 7521; $\quad$ (b)Balkenende, D. W. R.; Coulibaly, S.; Balog, S.; Simon, Y. C.; Fiore, G. L.; Weder, C. J. Am. Chem. Soc. 2014, 136, 10493.

(10) Seidel, C. A. M.; Kuhnemuth, R. Nat. Nanotechnol. 2014, 9 , 164.

(11) (a)Balaz, P.; Achimovicova, M.; Balaz, M.; Billik, P.; Cherkezova-Zheleva, Z.; Criado, J. M.; Delogu, F.; Dutkova, E.; Gaffet, E.; Gotor, F. J.; Kumar, R.; Mitov, I.; Rojac, T.; Senna, M.; Streletskii, A.; Wieczorek-Ciurowa, K. Chem. Soc. Rev. 2013, 42, 7571; $\quad$ (b)James, S. L.; Adams, C. J.; Bolm, C.; Braga, D.; Collier, P.; Friscic, T.; Grepioni, F.; Harris, K. D. M.; Hyett, G.; Jones, W.; Krebs, A.; Mack, J.; Maini, L.; Orpen, A. G.; Parkin, I. P.; Shearouse, W. C.; Steed, J. W.; Waddell, D. C. Chem. Soc. Rev. 2012, 41, 413.

(12) Stojakovic, J.; Farris, B. S.; MacGillivray, L. R. Farad. Discuss. 2014. DOI: $10.1039 / \mathrm{C}_{4}$ FDoooo6D

(13) (a)Sepelak, V.; Duvel, A.; Wilkening, M.; Becker, K.-D.; Heitjans, P. Chem. Soc. Rev. 2013, 42, 7507; (b)Kaupp, G. CrystEngComm 2009, 11, 388; $\quad$ (c)Morris, R. E.; James, S. L. Angew. Chem. Int. Ed. Engl. 2013, 52, 2163; (d)Suryanarayana, C. Prog. Mater. Sci. 2oo1, 46, 1.

(14) Garay, A. L.; Pichon, A.; James, S. L. Chem. Soc. Rev. 2007, $36,846$.

(15) (a)Braga, D.; Giaffreda, S. L.; Grepioni, F.; Pettersen, A.; Maini, L.; Curzi, M.; Polito, M. Dalton Trans. 20o6, 1249;

(b)Friscic, T. Chem. Soc. Rev. 2012, 41, 3493.

(16) (a)Rodriguez, B.; Bruckmann, A.; Rantanen, T.; Bolm, C. Adv.Synth.Catal. 2007, 349, 2213; (b)Stolle, A.; Szuppa, T.; Leonhardt, S. E. S.; Ondruschka, B. Chem. Soc. Rev. 2011, 40, 2317; $\quad$ (c)Wang, G.-W. Chem. Soc. Rev. 2013, 42, 7668.

(17) Chatterjee, T.; Ranu, B. C. R. Soc. Chem. Adv. 2013, 3, 10680.

(18) (a)Icli, B.; Christinat, N.; Tonnemann, J.; Schuttler, C.; Scopelliti, R.; Severin, K. J. Am. Chem. Soc. 2oo9, 131, 3154; (b)Kaitner, B.; Zbacnik, M. Acta Chim. Slov. 2012, 59, 670.

(19) (a)Bruckmann, A.; Krebs, A.; Bolm, C. Green Chem. 20o8, 10, 1131; (b)Almasi, D.; Alonso, D. A.; Balaguer, A.-N.; Najera, C. Adv.Synth.Catal. 2009, 351, 1123; (c)Bruckmann, A.; Rodriguez, B.; Bolm, C. CrystEngComm 2009, 11, 404; (d)Zhang, Z.; Dong, Y.-w.; Wang, G.-w.; Komatsu, K. Synlett 2004, 61; $\quad$ (e)Antesberger, J.; Cave, G. W. V.; Ferrarelli, M. C.; Heaven, M. W.; Raston, C. L.; Atwood, J. L. Chem. Commun. 2005, 892.
(20) Hsu, C.-C.; Lai, C.-C.; Chiu, S.-H. Tetrahedron 2009, 65, 2824.

(21) Orita, A.; Jiang, L.; Nakano, T.; Ma, N.; Otera, J. Chem. Commun. 2002, 1362.

(22) Hsu, C.-C.; Chen, N.-C.; Lai, C.-C.; Liu, Y.-H.; Peng, S.-M.; Chiu, S.-H. Angew. Chem. Int. Ed. Engl. 20o8, 47, 7475.

(23) Hara, K. O.; Yamasue, E.; Okumura, H.; Ishihara, K. N. J. Alloy. Compd. 2011, 509, S243.

(24) Bowmaker, G. A. Chem. Commun. 2013, 49, 334.

(25) (a)Friščić, T.; Halasz, I.; Beldon, P. J.; Belenguer, A. M.; Adams, F.; Kimber, S. A. J.; Honkimäki, V.; Dinnebier, R. E. Nat. Chem. 2013, 5, 66; (b)Halasz, I.; Puškarić, A. Kimber, S. A. J.; Beldon, P. J.; Belenguer, A. M.; Adams, F.; Honkimäki, V.; Dinnebier, R. E.; Patel, B.; Jones, W.; Štrukil, V.; Friščić, T. Angew. Chem. Int. Ed. Engl. 2013, 52, 11538.

(26) (a)Gavezzotti, A. Chem. Eur. J. 1999, 5, 567; (b)Gavezzotti, A. Model. Simul. Mater. Sci. Eng. 2002, 10, R1.

(27) (a)Bégin-Colin, S.; Girot, T.; Le Caër, G.; Mocellin, A. J. Solid State Chem. 200o, 149, 41; $\quad$ (b)Liu, X.; Liu, G.; Zhao, H.; Zhang, Z.; Wei, Y.; Liu, M.; Wen, W.; Zhou, X. J. Phys. Chem. Solids 2011, 72, 1245; $\quad$ (c)Matsuoka, M.; Hirata, J.; Yoshizawa, S. Chem. Eng. Res. Des. 2010, 88, 1169.

(28) (a)Nguyen, K. L.; Friscic, T.; Day, G. M.; Gladden, L. F.; Jones, W. Nat. Mater. 2007, 6, 206; $\quad$ (b)Friscic, T. Childs, S. L.; Rizvi, S. A. A.; Jones, W. CrystEngComm 20o9, $11,418$.

(29) Ito, A.; Tu, R.; Goto, T. Surf. Coat. Tech. 2010, 204, 2170.

(30) Braga, D.; Grepioni, F. Chem Commun. 2005, 3635

(31) de Loera, D.; Stopin, A.; Garcia-Garibay, M. A. J. Am. Chem. Soc. 2013, 135, 6626.

(32) Gracin, D.; Štrukil, V.; Friščić, T.; Halasz, I.; Užarević, K. Angew. Chem. Int. Ed. Engl. 2014, 53, 6193.

(33) Navrotsky, A.; Mazeina, L.; Majzlan, J. Science 2008, 319, 1635.

(34) Navrotsky, A. ChemPhysChem 2011, 12, 2207.

(35) Zhang, H.; Gilbert, B.; Huang, F.; Banfield, J. F. Nature 2oo3, 424,1025 .

(36) Hill, T. L. Thermodynamics of Small Systems (Parts I and II); Dover Publications, Inc New York, 1994.

(37) Bernstein, J. Cryst. Growth Des. 2011, 11, 632.

(38) (a)Braga, D.; Giaffreda, S. L.; Grepioni, F.; Chierotti, M. R.; Gobetto, R.; Palladino, G.; Polito, M. CrystEngComm 2007, 9, 879; (b)Shan, N.; Toda, F.; Jones, W. Chem. Commun. 2002, 2372.

(39) (a)Evora, A. O. L.; Castro, R. A. E.; Maria, T. M. R.; Rosado, M. T. S.; Silva, M. R.; Canotilho, J.; Eusebio, M. E. S. CrystEngComm 2012, 14, 8649; (b)Trask, A. V.; Shan, N.; Motherwell, W. D. S.; Jones, W.; Feng, S.; Tan, R. B. H. Carpenter, K. J. Chem. Commun. 2005, o, 880.

(40) Sanchez-Navas, A. Am. Mineral. 1999, 84, 1270.

(41) Cinčić, D.; Brekalo, I.; Kaitner, B. Cryst. Growth Des. 2011, 12, 44

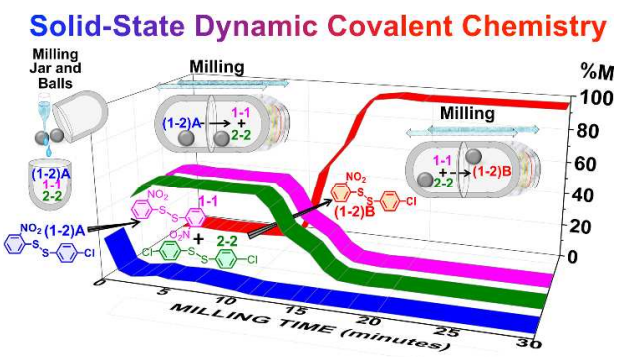


